Portland State University

PDXScholar

5-16-1977

\title{
The Use of Telegraphic Reading Material by Aphasic Patients
}

Sylvia Diane Tovey

Portland State University

Follow this and additional works at: https://pdxscholar.library.pdx.edu/open_access_etds

Part of the Speech and Hearing Science Commons, and the Speech Pathology and Audiology Commons

Let us know how access to this document benefits you.

\section{Recommended Citation}

Tovey, Sylvia Diane, "The Use of Telegraphic Reading Material by Aphasic Patients" (1977). Dissertations and Theses. Paper 2503.

https://doi.org/10.15760/etd.2499

This Thesis is brought to you for free and open access. It has been accepted for inclusion in Dissertations and Theses by an authorized administrator of PDXScholar. Please contact us if we can make this document more accessible: pdxscholar@pdx.edu. 
AN ABSTRACT OF THE THESIS OF Sylvia Diane Tovey for the Master of Science in Speech Communication: Bmphasis in Speech Pathology/Audiology presented May 16, 1977.

Title: The Use of Telegraphic Reading Material by Aphasic Patients

APPROVED BY MEMBERS OF THE THESIS COMMITTEE:

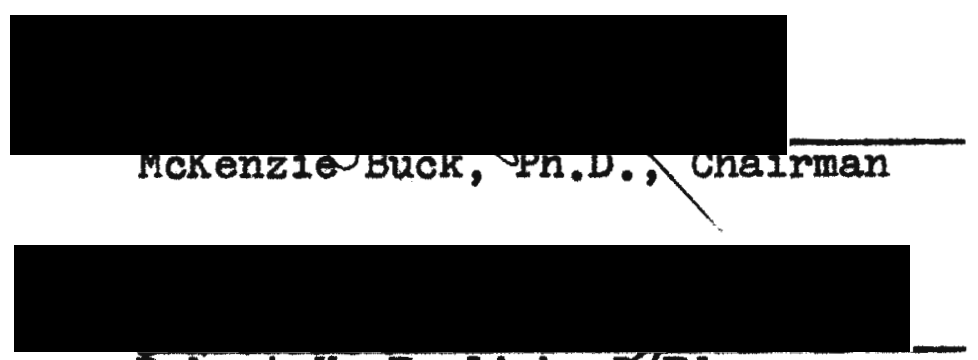

Robert H. English, E.Ed.
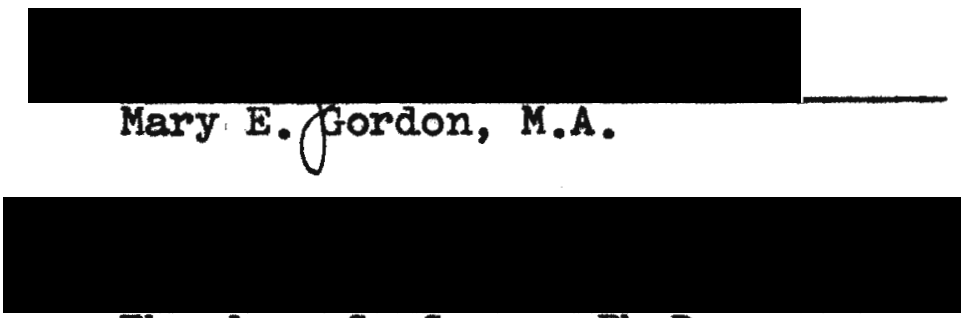

Theodore G. Grove, Ph.D.

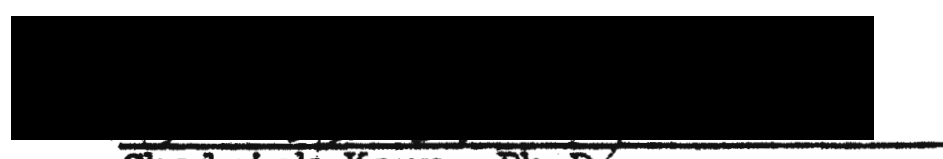

Chadwick Karr, Ph.D!

The purpose of this study was to determine if aphasic patients have significantly more correct answers for telegraphically written material when compared to normally written material. 
Twenty subjects from the greater Portland metropolitan area were selected to be included in this study. The ages of the subjects ranged from forty-two through sixty-five years with a mean of fifty-four years.

The test material consisted of two paragraphs controlled for fourth grade grammar and rocabulary and two paragraphs controlled for sixth grade grammar and vocabulary. A normally written and a telegraphically written paragraph were used for each of the four paragraphs for a total of elght test paragraphs.

The results of this study revealed no statistically significant difference for the magnitude of correct answers for the telegraphically written material; however, a significant number of subjects gave more correct answers for the telegraphic material at both the fourth and sixth grade levels.

These results demonstrate that it is easier for some aphasic patients to comprehend telegraphically written material than normally written material. Therefore, telegraphically written material may be of value for patients with aphasia who are relearning to read. This type of material may also be used for recreational reading when requested by aphasic patients. 
THE USE OF TELEGRAPHIC READING

\title{
MATERIAL BY APHASIC PATIENTS
}

\author{
by
}

SYLVIA DIANE TOVEY

A thesis submitted in partial fulfillment of the requirements for the degree of

\author{
MASTER OF SCIENCE \\ in \\ SPEECH COMMUNICATION \\ with emphasis in \\ Speech Pathology and Audiology
}

Portland State UnIveristy

1977 
TO THE OPFIGE OF GRADUATE STUDIES AND RESEARCH:

The members of the Committee approve the thesis of Sylria Diane Torey presented May 16, 1977.

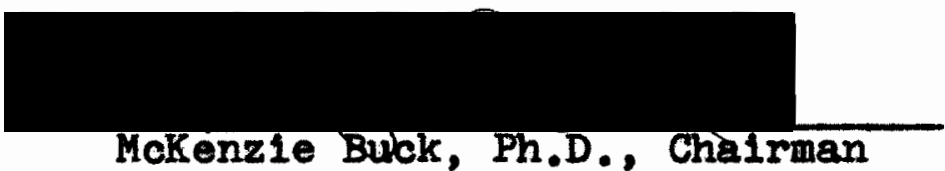

MCKenzie Buck, Ph.D., Chairman

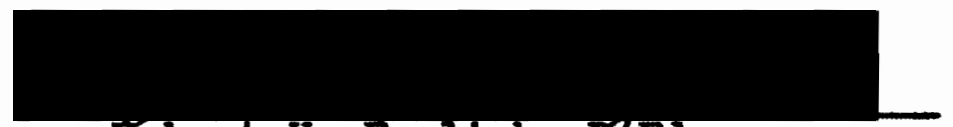

robert H. Engligh, bjsd.

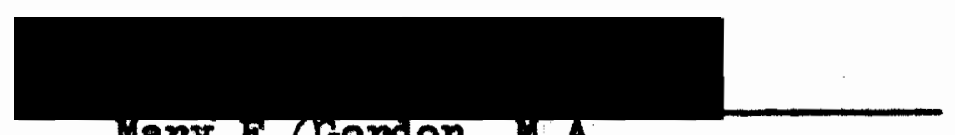

Mary E. Gordon, M.A.
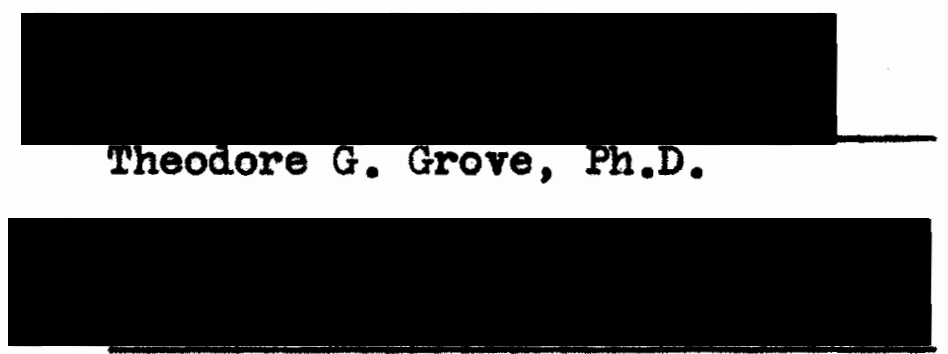

Chadwlck Karr, Ph.D.

APPROVED:

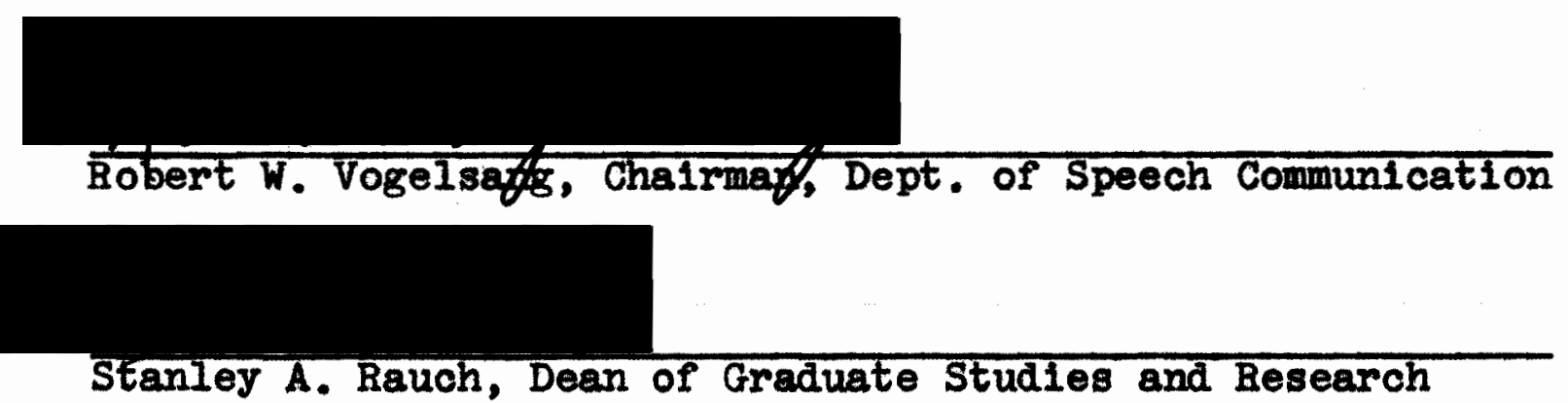




\section{ACKNOWLEDGMENTS}

I wish to express my sincere thanks and appreciation to:

Dr. McKenzie Buck for his guidance and support. Dr. Buck gave generously of his time to broeden my knowledge of the many parameters involving patients with aphasia. Without his assistance this thesis would not have been possible. Dr. Robert English and Mrs. Mary Gordon for their helpful suggestions and editing.

Dr. Theodore Grove for his expertise and assistance with the statistics necessary for this project. My thesis subjects who rery generously gave of their time and energy to complete a sometimes difficult task. Finally, to my husband Charles, my deepost thanks for his patience, support, and understanding over the past years. 
TABLE OF CONTENTS

PAGE

ACKNOWLEDGMENTS .................111

LIST OF TABLES .................. v1

LIST OF FIGURES . . . . . . . . . . . . . V111

CHA PTER

I INTRODUCTION AND STATEMENT OF PURPOSE . . 1

Introduction ......... 1

Statement of Purpose ....... 3

Definition ......... 4

II REVIEW OF THE LITERATURE . . . . . . 5

Background to Adult Aphasia..... 5

Language and Speech

Definitions of Aphasia

Etiology of Aphasia

Cerebral Dominance

Intellectual Functioning and

Language Problems in Aphasia

Early Remediation for Aphasia

Impairment of Reading in Adult Aphasic

Patients . . . . . . 16

Vocabulary Usage

Verbal Retention Span

Memory Span

Attention Span and Concentration

Effects of Patigue on

Concentration

Anxiety Tensions

Visual Field Anomalies

Visual Discrimination

Alexia

Management Guidelines for

Reading 
CHA PTER

PAGE

III

TESTS AND PROCEDURES . . . . . . . 35

Subjects . . . . . . . . 35

Pre-test Procedures . . . . . . 37

Questionnalre

Screening Test

Reading Test ........... 40

Test Formulation

Test Design

Administration

Data Analysis . . . . . . . 45

IV

RESUITS AND DISCUSSION . . . . . . 47

Results .. . . . . . . . 47

Discussion . . . . . . . . 57

V SUMMARY AND IMPLICATIONS . . . . . . . 65

Summary . . . . . . . . . . 65

Implications ........ 66

Clinical

Research

BIBLIOGRAPHY

APPENDICES

A READING HISTORY QUESTIONNAIRE . . . . 75

B SCREENING TEST . . . . . . . . . . 76

C TEST MATERIAL ............... 77

D SUBJECTS' AGE, READING AND TEST PROPIIES - 81 


\section{IIST OF TABLES}

TABIE

PAGE

I Summary of Besults of Subject Questionnalre ............ 38

II Total Number Correct Responses at the Fourth Grade Level . . . . . . . 48

III F Test, Analysis of Varlance at the Fourth Grade Level . . . . . . . 50

IV W1lcoxon T Ordinal-Rank Test on Normal

and Telegraphic Language for Fourth Grade Mater1al .. . . . . . . 51

V Total Number Correct Responses at the S1xth Grade Level ... . . . . . 52

VI $t$ Tests for Independent Means at the

S1xth Grade Level .. . . . . . . 54

VII F Test, Analysis of Variance at the

S1xth Grade Level . . . . . . . 55

VIII W1lcoxon T Ordinal-Rank Test on Normal

and Telegraphic Language for S1xth

Grade Material . . . . . . . 56

IX $t$ Tests for Dependent Means Comparing

Telegraphlc and Normal Paragraphs . . 58

$X$ Wilcoxon $T$ Ordinal-Rank Test Comparing

Fourth and S1xth Grade Material for

Normal Paragraphs . . . . . . . 59 
$\nabla 11$

$\begin{array}{ll}\text { TABLE } & \text { PAGE }\end{array}$

XI Wilcoxon T Ordinal-Rank Test Comparing

Fourth and Sixth Grade Material for

Telegraphic Paragraphs . . . . . 60 


\section{IIST OF FIGURES}

FIGURE

PAGE

1 Retina, Optic Badiation, and Hemisphere

Functions in the Perception of the

Visual fields ........ . . . 27

2 How a Sentence Is Perceived by Individuals

with Either a Right or Left Visual

Fleld Cut (Hemlanopsia) . . . . . 28

3 Control of Presentation of Grammar Style . . 43

4 Design for Administration of Test

Material . . . . . . . . . 43 


\section{CHAPTER I}

\section{INTRODUCTION AND STATEMENT \\ OF PURPOSE}

\section{INTRODUCTION}

Aphasia is an impairment in the use of language caused by injury to the dominant cerebral hemisphere of the brain (Taylor, 1958; Boone, 1965; Busk, 1971; and Mossman, 1976). Aphasia is not attributable to neuromuscular impairment of the speech musculature, mental deficiency, psychopathology, or dysfunction of the peripheral sense organs (Rusk, 1971; and Mossman, 1976).

When aphasia is present, there is a deficit in both the input and output systems of language. Any, or all, of the following intellectual parameters may be affected: 1) comprehending the speech of others; 2) reading; 3) recognizing objects; 4) performing mathematical functions; 5) speaking; 6) writing; 7) spelling; 8) counting; and 9) tellIng time (Taylor, 1958; Boone, 1965; Rusk, 1971; and Mossman, 1976). In addition, there also may be a reduction in the avallable expressive vocabulary, dysfunction in the use of grammar, involvenent of the verbel retention span, and confusion of letters as well as inability to use gestures, imitate movements, and pentomime appropriately (Rusk, 1971; 
and Mossman, 1976.

The first priority in language training is re-establishing verbal comprehension and expression. It is essential the individual with aphasia develop these parameters of language so he will be able to express himself adequateIy and understand others when they speak to him. Reading, writing, spelling, and mathematics are introduced into the training sessions as needed by the petlent after verbal skills are well established (E1senson, 1973). These "pencil and paper" tasks are taught in confunction with verbal language expression and comprehension combined with speech remediation for apraxia or dysarthria, if present.

Reading is usually introduced initially through 1tems necessary to every day living, such as the labels on food cans and street signs (Buck, 1968). Wepmen (1951) and Buck (1968) recommend individual words be read first. These words then can be copled, read aloud, and used in talking after reading. After the individual masters these initial reading tasks, he progresses to whatever type of reading is important to him, e.8., newspapers, perlodicals, or books.

When the aphasic patient first begins reading complete sentence and paragraph material, such as newspaper articles, he likely will have diffloulty understanding what he is reading. This difficulty is caused by a combination of a short memory span, reduced rocabulary, visual problems, and short attention span (Wepman, 1951; Berry and Eisen- 
son, 1956; Agranowitz and McKeown, 1964; Smith and Philippus, 1969; Halpern, 1972; and Elsenson, 1973).

Buck (1975) instructs certain aphasic patients, who are beginning to read, to select visually the words in each sentence which contain the meaning of the sentence. This technique calls for visual input, decoding, and rating of each word as to whether it is important to the meaning of the sentence.

An alternative method for inltial retraining in readIng would be to use material which omits the words which are not necessary for understanding the meaning of the paragraph. With this type of material, the aphasic individual would not have to selectively retain or ignore words as he reads; all words in each sentence would be necessary for comprehension of that sentence. This type of reading material has been used by the author with aphasic patients. In some instances, improved comprehension was noted. Therefore, the author desired to verify the accuraoy of this clinical observation under controlled research conditions.

\section{STATEMENT OF PURPOSE}

The purpose of this study was to determine if it was easier for the adult aphasic patient to read telegraphically written material and comprehend its meaning than it is to read and comprehend normally written material.

One hypothesis was tested: 
Adult aphasic patients will provide significantly more correct answers for telegraphlcally written materlal at the fourth grade and sixth grade levels than for normally written material for each grade level.

In an effort to answer this hypothesis, these additlonal questions were asked:

1) Would there be a relationship between topics and the number of correct responses?

2) Would there be a relationship between grade level and the number of correct responses?

3) Would there be a relationship between latency of response and the number of correct answers?

\section{DEPINITION}

In this investigation "telegraphic writing style" is defined operationally as follows: naterial which is written In the telegraphic atyle has the parts of grammar omitted which are not essential to the understanding of the meaning of the sentence. These parts of grammar include auxillary verbs, adjectives, adverbs, and articles (Harrison, 1947; McNe11, 1970; and Menyuk, 1971). An example of telegraphically written material is: "Cat climbed tree," instead of the normal writing style: "The cat climbed up the tree." 
CHAPTER II

\section{BEVIEW OF THE LITERATURE}

The present chapter will seek to bring together information from the literature dealing with adult aphasia on a two-fold basis: 1) beckground information based on clinical observations, experionces, and research that seek to describe the condition known as aphasia in adults; and 2) Information related to the impalrment of the reading process as observed in the adult patient with aphesia. Specifically, these kinds of data will be presented below under two major headings: 1) a background to adult aphasia; and 2) impairment of reading in adult aphasio patients.

\section{BACKGROUND TO ADUIT AFHASIA}

\section{Lensuage and Speech}

Language is the means by which humans communicate with one another. It 18 also the means by which each individual thinks, plans his actions, and is aware of what is transpiring in the vorld around $\mathrm{him}$. Ianguage is composed or symbols which are an arrangement of discernible stimuli (erents) which are elther audible and/or visible, and sometimes tactile (Elsenson, 19718). Humans recelve meaning from symbols by the association of a symbol with its corre- 
sponding event. For example, an association is established between the symbol cat and the object (event), a smell animal covered with fur, which meows and purrs. The process of symbol and object association starts during infancy and continues through the lifetime of the individual.

Language is the arrangement of symbols according to semantic and grammatical rules into a system employed for the purpose of communication (Perkins, 1971). The ability to use language is dependent on memory, 1.e., the power of "reproducing and identifying what has been learned or experienced" (Ponfield and Roberts, 1959). As an individual derelops from a child into an adult, an ongoing process takes place in the brain--the growth of the language system. Penfleld and Roberts (1959) hypothesize that language is besed on: 1) a memory for concepts; 2) a memory for experiences; and 3) a memory for words. There is formed in the brain a ganglionlc equivalent for a word (words) and a ganglionic equivalent for a concept (concepts) with experience, over the years, continuing to reinforce neuronsl interrelationships between the two.

Speech is the oral communication medium of a linguistic code. Speech is the most widely employed of all language modalities and in some instances, such as illiteracy, it may be the only language system used by some individuals. Other language mediums are reading, writing, and gesturing. Specialized communication systems for visually and aurally handicapped individuals include braille and sign language 
(Eisenson, 1971a).

\section{Definitions of Aphasia}

Aphasia is a disorder reducing the use of language. The definition of aphasia differs according to whichever author is cited. McConnell (1974) stated aphasia is the inability to recognize the meaning of words. He said the aphasic patient will not be able to speak or write meaningfully. Schuell et al. (1964) and Schuell (1974) proposed the theory that aphasia is a general deficit that crosses all language modalities and may or may not be compounded by other sequelae of brain damage, such as reduction of available vocabulary, Impaired verbal retention span, and impairment in the production of messages. Darley (1964) advanced the theory that aphasia is a symbolic communication disorder resulting from the impairment of some central, integrative process which makes possible the association of old, learned stimuli and new stimuli. There is an impairment of comprehension, formulation, and use of the human symbol system. Darley (1964) stated the aphasic impairment is not the result of mental defect, poor motor control, or the restriction of sensory input. Penfield and Roberts (1959) defined aphasia as a disturbence in speech, comprehension of speech, naming, reading, or writing. Any one or more of these language modalities may be disturbed. Penfield and Roberts (1959) agreed with Darley (1964) that aphasia is not the result of a disturbance of the mechanism of articulation 
or involvement of the peripheral nerves, nor due to general mental insufficlency. E1senson $(1960,1971 a)$ stated aphasla is a subtractive disturbance of language with an impairment in the ability to deal with symbol activity and related areas. There is a reduced likelihood that the aphasic Individual involved in a communication situation will understand the speech of others or be able to produce an appropriate verbal formulation.

All of these definitions have in common the concept that aphasia is an impairment in the use of language. Aphasia is characterized by an inability to receive and classify symbols and an inability to relate symbols to objects (Wood, 1960). The inability to comprehend language is often accompanied by an inability to formulate language. This disability not only involves verbal language but also generally affects the processes of reading and writing. Along with these disabilities, there is also a reduction in available vocabulary and a shortened rerbal retention span (Schuell et al., 1964). Elsenson (1971a) noted the deaf aphasic patient may also be impaired in his ability to use language. This disability is caused by a deficit in the formulation and comprehension of visible signs, sign language.

The aphasic individual is impaired in the ability to use propositional speech. According to Elsenson (1971a), propositional speech is Iinguistic symbols used for the purpose of communication, and is unique for the speakers 
and the situation. Automatic speech 18 generally preserved In the aphasic patient. This type of speech includes emotlonally charged utterances, cliches, expletives, and verbal series, e.g., counting, reciting the alphabet, and soclal gestures. Automatic speech is triggered in a set formulation and does not require specific linguistic encoding which is necessary for propositional speech.

\section{Et1ology of Aphasia}

Aphasia is the result of brain injury which occurs in many ways. Cerebro-vascular accidents, the major etiology of aphasia in people of middle and old age, include thromboses, embollsms, aneurysms, hemorrhages, and ischemias, with embolisms, hemorrhages, and thromboses being the most common (Wepman, 1951; Halpern, 1972; and E1senson, 1973). Physical trauma to the brain, gun shot wounds, automobile acc1dents, and falls can cause aphasia as well as brain tumors and their extirpation, abscesses, infectious diseases, and degenerative diseases (Boone, 1965; Taylor and Warrington, 1971; Halpern, 1972; and Elsenson, 1973). According to Shafer et al. (1974), the older patient, over sixty-five years of age, does not recover from the effects of a cerebro-vascular accldent as well as younger patients. The older patient is prone to have pre-existing hypertension, arteriosclerosis, atherosclerosis, diabetes, prodiabetes, or a combination of these disorders which innibit, or destroy, collateral oirculation and diminish the 
recovery potential of the patient (UIlman, 1962; Sherman, 1964; Re1tan, 1966; and Keenan and Brazzel1, 1975). Rusk (1971), Zankel (1971), and Keenan and Brazzell (1975) stated the younger patient with external etiology may be expected to show more recovery from aphasia because of a lack of cardio-vascular disorders wich inhibit recovery potential.

\section{Cerebral Dominance}

Many studies have been conducted with the intent of establishing the dominant language hemisphere. There is general agreement that the left hemisphere of the brain controls speech and language for right handed Individuals (Weinstein and Teuber, 1957; Luria, 1966a; and Goldberg and Schiffman, 1972). Elsenson (1971b), however, noted approxImately ten percent of the right handed population may have language dominance controlied by the right hemisphere of the brain.

The controversy over brain dominance for language function occurs with regard to both the left handed and ambidextrous populations. Penfield and Roberts (1959) stated the left hemisphere is dominant for language in the left handed individual unless there has been an early trauma or congenital malformation in that hemisphere; then language dominance becomes the function of the right hemisphere. Wertz et al. (1977) reported on a case of congenital left hemisphere arteriovenous malformation in which the subject was left handed and right hemisphere dominant for language. 
The results of this case history are in agreement with the theory of Penfield and Boberts (1959). Halpern (1972), after reviewing the literature, found it is not clear which hemisphere controls language in the left handed individual. Goldberg and Schiffman (1972) propose the figure of twentyelght percent of the left handed population having language dominance in the right cerebral hemisphere. Eisenson's (1971b) emperical observation is that twenty to thirty percent of the left handed population has right hemisphere dominance for language.

Cerebral dominance for language for the ambidextrous individual is less clearly delineated than for the left handed individual as most of the literature reviewed by this author does not discuss the ambidextrous individual. Eisenson (1973) advanced the theory that this small group of people may have a more bilateral representation in the brain for language than the left handed population; however, he groups ambidextrous and left handed individuals together when considering aphasic disturbances.

Intellectual Functioning and Language Problems in Aphasia

No matter which hemisphere is dominant for speech and language, aphasia may occur when the dominant hemisphere is damaged. When aphasia is present, the patient presents a lower level of intellectual functioning than he possessed before the trauma occurred. Eisenson (1973) warns that the term intellectual functioning must be used instead of intel- 
Iigence to aroid the implication there is a nonreversible impairment of intelligence following brain damage. When an I.Q. test is administered to an aphasic patient, his Full Scale I.Q. score will be lower than it was before the traume (Wepman, 1951). His Verbal I.Q. also will generally be lower than his Performance I.Q. (Weinstein and Teuber, 1957; Wood, 1960; and Matarazzo, 1972). Additionally, there generally will be a lower test score on the Wechsler Memory Scale which measures immediate and remote recall (Eisenson, 1960; and Matarazzo, 1972).

Matarazzo (1972) stated the following variables must be taken into account when considering the magnitude and of fect of the brain damage and the test scores:

1) laterality of lesion (right or left hemisphere);

2) regional location or site of lesion within hemisphere;

3) causal agent(s) creating lesion(s);

4) age of patient when lesion was incurred;

5) time interval between damage and testing;

6) condition of the patient (e.g., drugs he might be taking, etc.) at time of assessment apart from brain damage;

7) lateral motor and higher cortical function dominance;

8) premorbid condition of patient; and

9) severity and extent of lesion.

When considering intelligence test scores of aphasic 
patients, it is important to remember several factors. Some aphasic patients cannot deal with purely verbal tests since they have difficulty understanding the meaning of words and grammar (Iuria, 1966a). There may be a rapid extinction of word traces which reduces comprehension. These patients may also have difficulty forming verbal responses to the test items (Iuria, 1966a). All of these language deflcits will lower the Verbal I.Q.

The test atmosphere may also influence test results. Wood (1960) noted aphasic patients perform poorly on timed tests. According to Eisenson (1973), anxiety caused by timed psychological evaluation causes a reduction in ideal testing conditions. The results obtained from timed tests may not reflect optimum intellectual functioning. According to a study by Luria (1966a), intelligence tests should be administered as untimed tests to obtain results as good as possible from the patient.

According to Wepman (1951), the purpose of Intelligence testing with aphasic patients should be to determine the ability of the patients to respond to problems at that time. The nature of the aphasic individual's problem limits his response pattern, depenaing on the severity of the organic trauma. Wepman (1951) warned the examination may be measuring the aphasia rather than the intellectual functioning of the individual.

It is thought best that, whatever the results be, they should be considered as inferential only. Quantitatively they offer little or no valid information, 
and even qualitatively they must be understood and used only in the light of the language handicap (Wepman, 1951).

Accompanying the lowered level of intellectual functioning is a regression to earlier developmental stages in the use of language (Wepman, 1951; and Par1si and Pizzamig110, 1970). Using U.S. Army records, Wepman (1951) established a mean educational grade level of 9.85 years for his subjects prior to brain injury. After the trauma occurred, but before training proceeded, the mean educational grade level was 3.6 years; thus, there was a 10ss, on the average, of six grade levels in the aphasic individual.

According to a study by Keenan and Brazzell (1975), aphasic patients who had a good formal education, or who continued to read and write after finishing school, tend to lose their grasp of language to a lesser degree than ind1viduals who were illiterate or did not continue to use language skills. Keenan and Brazzell (1975) hypothesize that the more literate person seemed to have language more deeply embedded in the central nervous system which aids in the recovery process.

\section{Early Bemediation for Aphasia}

Language stimulation often is initiated while the aphasic patient is still in the hospital, as soon as he is aware of what is occurring around him (Wepman, 1951; Perkins, 1971; and Eisenson, 1973). An Instance of this stimulation occurs when the patient uses nonverbal language 
such as a grunt or gesture to request an object and someone verbally supplies the appropriate name when giving the patient what he desires, e.g., "Here's a shirt" (Smith, 1967; and Zankel, 1971). Pairing the verbal label with the object helps stimulate the use of language. Elsenson (1971c) stated language stimulation must begin as early as possible so the aphasic patient does not resort to habitual use of nonverbal communication or reconcile himself to not communicating with others and withdraw from social interaction.

Informal language retraining procedures continue to be used by the family when the aphasic patient returns home from the hospital (Buck, 1968). At home, the naming process should include items of clothing and household objects which can be seen, felt, or heard, such as chalr, table, store, and telephone. This type of language stimulation is similar to the process of language development of children, and is a necessary first step in the reacquisition of language usage (Wepman, 1951; and Buck, 1968).

Language training provided by a speech pathologist should begin while the patient is in the hospital. This service consists of support and reassurance for the aphasic patient and counseling for the family (Berry and Elsenson, 1956; Perkins, 1971; Halpern, 1972; and Buck, 1975). Formal testing and training sessions should be postponed until after the aphasic patient is neurologically stable, and has inltiated physical mobility, continence, and eating skills (Wepman, 1953; and Buck, 1975). Two factors to consider 
before beginning formal management sessions are psychological readiness and spontaneous recovery. Psychological readiness for therapy is neoessary if the patient is going to progress. If the patient indicates he does not want to start therapy, he probably is not ready to benefit from formal remediation sessions (Taylor, 1958; and Smith, 1967).

Spontaneous recovery of language begins when edema caused by brain trauma begins to subside. With a decrease in edema, neurons surrounding the site of damage begin to reactivate and function or there may be an adaptive transfer of function to another area of the brain (Eisenson, 1973; and Mossman, 1976). Taylor (1958), Eisenson (1973), Keenan and Brazzell (1975), and Skelly (1975) recommended therapy be initiated during the first six weeks post-trauma to utilize spontaneous recovery. They state that therapy started during this time enhances the process of language recovery since the aphasic patient is generally receptive to external stimuli.

\section{IMPAIBMENT OF READING IN ADULT APHASIC PATIENTS}

As discussed above, reading is one of the language modalities used for the purpose of communication. When an individual reads, he is applying a broad set of linguistic skills to one language medium (Hartstein, 1971). Beading is based on the recognition of the meaning of individual words and sometimes entire phrases. When an indiridual begins to 
read, he must percelve and analyze each letter, process letter groups into their corresponding phonetic structure, and then comprehend the meaning of what is written. With practice, reading becomes an automatic process which rarely employs analysis and synthesis of individual letters (Luria, 1966a).

According to Gardner et al. (1975), virtually all aphasic patients experience difficulty, to some degree, with oral reading, or reading comprehension. This difficulty may occur in relative isolation with other language modalities remaining intact. Conversely, in the case of transcortical aphasia, reading may be better preserved than other language skills (Gardner et al., 1975). Usually all areas of receptive and expressive language are disrupted to some extent.

The remainder of this chapter is devoted to a discussion of linguistic and nonlinguistic disturbances associated with aphasia and how these defects affect the ability of the aphasic patient to read.

\section{Vocabulary Usage}

Vocabulary usage is one of the perameters of language which is affected by the aphasic disturbance. There is a reduction in the rocabulary used by the aphasic patient (Wint, 1967). The words that are retained are those that were learned first or those that were used most often (Schuell, 1974). When anomia is present, it is character- 
lzed by a loss of all but the most frequently used words (Halpern, 1972).

Eisenson (1954) stated the correct use of avallable vocabulary depends, to a degree, on the type of task required of the individual. It is easiest for the aphasic patient to name an object present in his environment. It is more difficult for him to name a picture of an object, and the most difficult task is for him to identify the object from a written representation, even if the word for the object is in the oral vocabulary of the subject. As 1llustrated by Eisenson (1954), the comprehension of visible symbols, reading, is more likely to present difficulties for the individuel with aphasia than the comprehension and expression of oral language.

According to the emperical data of Schuell (1965), Shewan and Canter (1971), and Halpern (1972), errors in vocabulary Increase as the general frequency of usage of the words decreases. For example, the word comb is less common than the word hand since comb occurs one time per 3,500 words compared to hand which occurs one time per 500 words (Thorndike, 1944). There is also a decrease in correct usage as the length of the word increases (Schuell, 1965; Shewan and Canter, 1971; and Halpern, 1972).

\section{Verbal Retention Spen}

A reduced verbal retention spen, which is a frequent, well-recognized clinical phenomenon, will also affect the 
ability of the aphasic individual to read and retain enough words to comprehend the meaning of a sentence or paragraph (Wepman, 1951; Schuell et al., 1964; Schuell, 1965; Brooks, 1975; and DeRenzi and Nichell1, 1975). Lurla (1966b) defined the verbal retention span as the ability to perceive, retain, and reproduce a series of serially ordered acoustic or visual signals. When this process breaks down, the person may not be able to retain more than two to three words at a given time. The first or last word may be lost or the order of the message units may be altered (Sohuell et al., 1964). Luria (1966b) 1llustrated this by giving a patient with aphasia the verbal series "house-cat-ball." The patient repeated this series as "house-ball-and something else." He had forgotten the order in which the serles was presented. This breakdow in serial order retention also applies to numbers. Iuria (1966b) dictated the number series "3-0-9-8-2" which the patient repeated as "3-0-8-2-9." When the patient repeated the series a second time, the order was "3-8-2-0-9." The patient was aware of his incorrect reproduction but was unable to correct his response. Beduction of verbal retention span also affects the aphasic patient when material is presented visually. An aphasic patient may have difficulty reproducing a series of numbers when they are presented one at a time. This difficulty can be alleviated by presenting the visual series as a whole whereby the individual can recognize the pattern of the series (Lur1a, 1966b). 
ability of the aphasic individual to read and retain enough words to comprehend the meaning of a sentence or paragraph (Wepman, 1951; Schuell et al., 1964; Schuell, 1965; Brooks, 1975; and DeRenz1 and Nichell1, 1975). Luria (1966b) defined the verbal retention span as the ability to perceive, retain, and reproduce a series of serially ordered acoustic or visual signals. When this process breaks down, the person may not be able to retain more than two to three words at a given time. The first or last word may be lost or the order of the message units may be altered (Schuell et al., 1964). Luria (1966b) 1llustrated this by giving a patient with aphasia the verbal series "house-cat-ball." The patient repeated this series as "house-ball-and something else." He had forgotten the order in which the series was presented. This breakdown in serial order retention also applies to numbers. Luria (1966b) dictated the number series "3-0-9-8-2" which the patient repeated as "3-0-8-2-9." When the patient repeated the series a second time, the order was "3-8-2-0-9." The patient was aware of his incorrect reproduction but was unable to correct his response.

Beduction of verbal retention span also affects the aphasic patient when material is presented visually. An aphasic patient may have difficulty reproducing a series of numbers when they are presented one at a time. This difficulty can be alleviated by presenting the visual series as a whole whereby the individual can recognize the pattern of the series (Luria, 1966b). 
ability of the aphasic individual to read and retain enough words to comprehend the meaning of a sentence or paragraph (Wepman, 1951; Schuell et al., 1964; Schuell, 1965; Brooks, 1975; and DeRenzi and Nichell1, 1975). Luria (1966b) defined the verbal retention span as the ability to perceive, retain, and reproduce a series of serially ordered acoustic or visual signals. When this process breaks down, the person may not be able to retain more than two to three words at a given time. The first or last word may be lost or the order of the message units may be altered (Schuell et al., 1964). Luria (1966b) illustrated this by giving a patient with aphasia the verbal series "house-cat-ball." The patient repeated this series as "house-ball-and something else." He had forgotten the order in which the series was presented. This breakdown in serial order retention also applies to numbers. Iuria (1966b) dictated the number series "3-0-9-8-2" which the patient repeated as "3-0-8-2-9." When the patient repeated the series a second time, the order was "3-8-2-0-9." The patient was aware of h1s incorrect reproduction but was unable to correct his response.

Reduction of verbel retention span also affects the aphasic patient when material is presented visually. An aphasic patient may have difficulty reproducing a series of numbers when they are presented one at a time. This difficulty can be alleviated by presenting the visual series as a whole whereby the individual can recognize the pattern of the series (Luria, 1966b). 
A reduced verbal retention span affects all language modalities. The aphasic patient may not be able to retain enough serially ordered words to comprehend the speech of others. He loses his thought pattern when verbalizing. When the individual with aphasia reads, he may forget what was in previous sentences and paragraphs. Schuell et al. (1964) are of the opinion errors in reading reflect a reduction of avallable vocabulary; however, reading difficulties stem primarily from a reduced verbal retention span. According to Schuell (1965), Shewan and Canter (1971), and DeRenzi and Nichell1 (1975), it is easier for the aphasic individual to read and retain material from a sentence than it is for him to read and understand a paragraph. When reading a paragraph, an aphasic individual will lose the meaning because by the time he reads the last sentence he will have forgotten what he read in the previous sentences. His verbel retention span has been overloaded by trying to retain sufficient linguistic chunks to form meaningful relationships (Schuell, 1965; and Perkins, 1971). Farrell (1969) has described the reduction of rerbal retention span which affected Patricia Neal after her cerebro-vascular accident and caused reading difficulties:

...she was wallowing in mid-paragraph now, ticking the words off with her fingers, piling them up in the air with no sense of where they were leading and little memory of where they had begun.

Schuell (1965) has allowed for a reduced verbal retention span in her test, the Minnesota Test for the Differen- 
tial Diagnosis of Aphasia (MPDDA). In this test, there is a paragraph reading section which has a reduced sentence length and a simplified sentence structure. The rocabulary of the paragraph is described as an easy adult reading level. Schuell et al. (1964) rated the words in the paragraph as being at the fourth grade level. The test is not timed and the subject may reread the paragraph to find answers to the questions which follow the paragraph. The object of the sub-test is to measure the subject's ability to obtain meaning from the printed page.

\section{Memory Spen}

The process of memory is a summation of the sequence of reception, registration, retention, and recall of stimul1 (Mossman, 1976). The stimulus is receired by the organism, dependent on the intactness of attention, receptive language function, and perceptual processes. Then the new stimulus is either registered or lost. If the stimulus is registered by the individual, it is retained in storage whereby it is organized with previous experience. Memory traces are recalled into consclousness by a voluntary effort or upon the provocation of an associated stimulus (Mossman, 1976).

Along with a reduced verbal retention span, the individual with aphasia may have defects of memory. Schuell et al. (1964) said the aphasic patient has not lost words and concepts stored in memory, but he has difficulty re- 
trieving them. The memory defect is one of recall and is associated with an impaired verbal retention span.

Research by Levin et al. (1976) assessed the memory defects of twenty-four subjects with head injuries which caused neurological deficits, brain stem involvement, or aphasia. The test results ranged from severe memory defects to normal memory function with five aphasic subjects falling in the severe range and two aphasic subjects scoring in the normal range. Levin et al. (1976) found the time lapse, e.g., two months to a year, between the trauma and testing was not positively related to the performance of the subjects. The results indicated there was a disproportinate representation of aphasio disturbances among head injured patients with impairments of memory.

\section{Attention Span and Concentration}

Another aspect which affects the ability to read is a short attention span combined with concentration difficulties (Taylor, 1958; Hodgins, 1964; and Smith, 1967). According to Mossman (1976), for a person to have an attention span adequate to recelve new information, he must be able to concentrate on a specific stimulus with freedom from distractions in the environment. Wepman (1951) hypothesized a short attention span and lack of concentration is due to the inability of the patient to integrate his thought processes and focus on the task at hand. The individual with aphasia must make an increased roluntary effort to 
concentrate on what is happening at the present moment (E1senson, 1954).

Wint's (1967) observation from his personal experience tends to support this view. He noted after his stroke and the onset of aphasia, he did not have the power of continuous concentration necessary for reading. When he concentrated on the beginning of a sentence, he was not able to gain information from the end of the sentence; when he concentrated on the end of the sentence, what he had read in the first part of the sentence eluded him.

\section{Effects of Patigue on Concentration}

The increased concentration necessary to attend to written material may cause an increase in fatigability which is a concomitant factor in aphasia (Buck, 1975). Fatigue will impair the ability of the aphasic patient to concentrate and he will not be able to function anywhere near his potential (E1senson, 1973). Longerich and Bordeaux (1954) and Ullman (1962) recommend management sessions be short enough to circumvent fatigue. They stated increased fatigue causes fallure in language reacquisition and, over time, fallure will impede progress in recovery from aphasia.

\section{Anxiety Tensions}

Another concomitant factor in aphasia is a high level of anxiety. According to Vllman (1962) and Keenan and Brazzell (1975), the aphasic patient may be highly anxious which is not compatible with the ability to use available 
language skills.

Matarazzo (1972) discussed two types of anxiety: transient, situational (state) anxiety and chronic, enduring (trait) anxiety. Studies suggest state anxiety is related to a specific situation and can be measured by: 1) the subject's self-report on the Sarason Test Anxiety Questionnaire or the Zuckerman Affect Adjective Check L1st; 2) standardized experimenter-individual situational-behavioral approaches, e.g., threat of electrical shock, report of subject's inferior performance or inducing time pressure with a stop watch; or 3 ) a combination of two or more of the anxiety measures. Matarazzo (1972) found state anxiety can be varied by a high-or low-pressure environment and negative or positive instructions and comments given by the clinician.

Trait anxiety does not vary with the situation, but is reasonably stable within the individual. The only time trait anxiety raries is in the presence of situational stress (Matarazzo, 1972). Wint (1967) reported a constant state of trait anxlety after his stroke. He said his anxiety was caused by his inability to perform at pre-trauma levels and his knowledge of his inadequacy. When working with the aphasic patient, the clinician should be aware of both state anxiety and trait anxiety. The patient may be in a constant state of chronic, trait anxiety caused by apprehensiveness about his present condition compared to his pre-trauma capabilities and misgivings 
about his ability to improve (Wepman, 1951). Trait anxiety can be increased by situational anxiety during management segsions when the patient tries to read at levels incompatible with his present functional language skills.

The clinician can reduce situational anxiety by providing success during each management session. Day-to-day success will reduce anxiety; then the patient will be more able to attend to deta1ls and appreciate his own progress (Wepman, 1951).

\section{Visual Field Anomalies}

Visual field defects may also cause difflculty for the Individual with aphasia (Darley, 1964; and Schuell et al. 1964). Visual acuity must be tested and corrective lenses prescribed if necessary; however, the defects associated with brain trauma are those of the visual fleld (Buck, 1968). The most common fisual fleld defect is some degree of hemlanopsia which is a partial or complete 1088 of one-half of the visual fleld. The leston which causes hemlanopsia and other visual fleld defects may occur in the eye which recelves the stimulus, the optic radiation which transmits the stimulus, or the visual cortex which appreclates the stimulus (Wepman, 1951; Lur1a, 1966a; and Moss$\operatorname{man}, 1967)$.

The laterality of the visual fleld out refers to the side of the affect vision. A right visual fleld cut implies imperfect vision to the right sides of the patient's 
visual fields in both eyes; a left visual field cut implies imperfect vision to the left sides of the patient's visual fields in both eyes. A field cut on either side may be partial or complete. Homonymous hemianopsia indicates the visual field defect is identical within the corresponding visual fields of both eyes (Buck, 1968 and Mossman, 1976). (See Figure 1.)

If an individual has blindness of the left visual fields, he will not begin reading at the left margin of the page but will begin in the middle of the page. With right visual field blindness, the patient will start reading at the left margin and infer the content of the right sides of the page. (See Pigure 2.)

According to Mossman (1976), patients with a right visual field deficit are more likely to compensate for their defect while reading than those with a left visual field deficit. According to Luria (1966a), a left visual field cut is often accompanied by agosognosia which is a lack of awareness or denial of illness or disability. Aphasic patients with agosognosia fail to recognize or do not correctly interpret sensory stimuli (Darley, 1964). The aphasic patient with left visual field hemianopsia generally cannot appreciate his visual disability and compensate for it (Luria, 1966a). Therefore, Mossman (1976) recommended drawing a colored line down each margin of the page the aphasic patient will be reading. The patient is then instructed to read from the left colored line until he reaches 


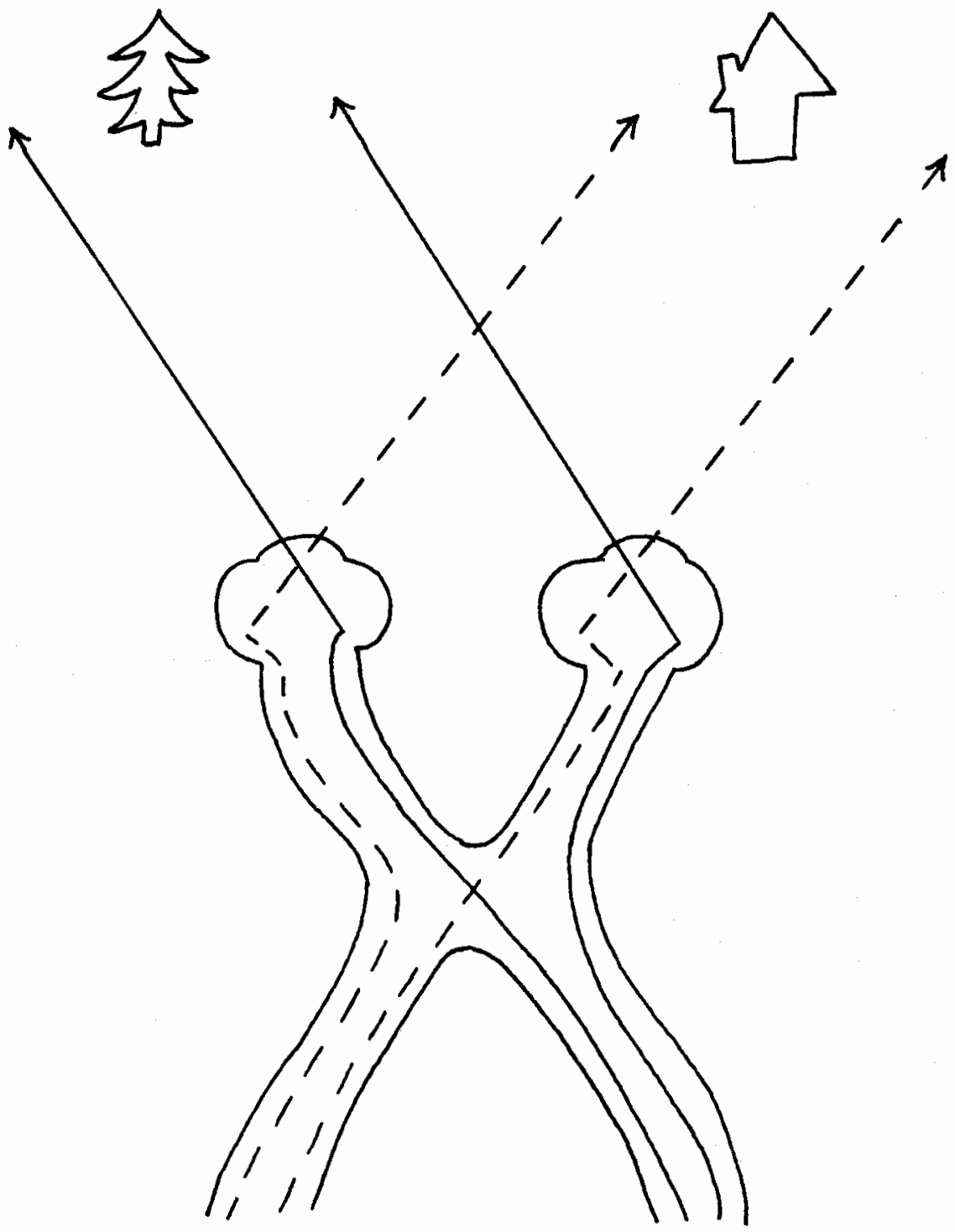

Figure 1. The tree in the left visual field is percelved by the nasal (medial) retina of the left eye and the temporal (1ateral) retina of the right eye. The fibers from the nasal retinas decussate at the optic chiasm such that the perception of the left field of vision becomes a $r$ ight hemisphere function and vice versa (Mossman, 1976). 
WE LIVE NORTH OP TOWN

A person with a right visual field cut will percelve the above sentence as:

WE LIVE NORTH

\begin{abstract}
A person with a left visual field cut will percelve the above sentence as:

NORTH OF TOWN

or:
\end{abstract}

TOWN

Figure 2. How a sentence 1s percelved by individuals with elther a right or left visual fleld cut (hemianopsia) (Mossman, 1976). 
the right line. This external reminder should be used when reading therapy begins, if the patient does not compensate for his visual field defect. The colored lines can be omitted when the patient learns to compensate for his deficit. other visual field defects may also be caused by lesions on the eye, optic radiation, or visual cortex. Scotoma is a dark spot on the visual field. The dark area may occur in the middle of the visual field or may be a dark zone surrounding the center of the visual field (Gould, 1936). Obfuscation (cloudiness), or diplopia (double vision) may be present or blurring or intermittent crowding of words within the range of the visual field (Schuell, 1965. 1974, Smith, 1967, Buck, 1968, 1975, Parrell, 1969, Poppel and Shattuck, 1974). All of these visual problems will also interfere with the ability to read.

Poppel and Shattuck (1974) conducted research using twelve subfects with visual field defects (hemianopsia, complete quadrantanopsia, absolute or relative scotoma) and ten control subjects with no visual field defects. The results indicated that the subjects with visual field defects took twice as long to read the test material as the normal controls. Poppel and Shattuck (1974) concluded that 10sions of the central visual pathways appear to produce slowing down in the processing of information.

\section{Visual Discrimination}

Disturbances of visual discrimination or recognition 
of visual symbols may be experienced by the patient with aphasia. When the impairment is severe, the individual may be unable to discriminate one letter from another (Schuell, 1974). With a milder impairment, the aphasic patient may have difficulty discriminating between the upper case letters EF, WM, $C G, Q Q$, and the lower case letters pdbg, tf, hn, ur, um, and mn (Schuell, 1965). Impaired discrimination may also extend to words. The individual may read match as match, dark as park, store as stone, and horse 28 house. According to a long-term study by Schuell (1974), in some instances when an aphasic patient has disturbed visual discrimination, he will have to decipher each letter individually and spell the word before he can recognize it. If this disorder is combined with a reduced verbal retention span, the patient may forget part of the word while spelling it. As a regult, he will make more mistakes on long words than short ones (Schuell, 1974).

\section{Arexia}

Alexia, or acquired dyslexia, is a disturbance in the evaluation and comprehension of written symbols when presented only through the visual modality (Longerich and Bordeaux, 1954, and Hartstein, 1971). This disorder, in the context considered here, is a result of the brain injury and did not exist in the individual prior to the trauma (Wepman, 1951, and Hartstein, 1971). Alexia is possibly related to an inability to revisualize or reauditorize the symbol. Thus, 
the visual symbol is not retained for a sufficient period of time for a symbol-object association to be established (Wood, 1960). Alexia will cause reading disabilities, but other parameters of language will not be affected by this disorder (Woods and Poppel, 1974).

According to Luria $(1966 \mathrm{a}, \mathrm{b})$, alexia consists of two types: alexia caused by lesions to the occipital cortex (optic alexia) and alexia which is the off-shoot of aphasia. Optic alexia is divided into literal and verbal alexia. When an aphasic patient has ilteral alexia, he is unable to perceive indiridual letters and their cue value. With 11teral alexia, letters lose their meaning. Patients with rerbal alexia can recognize individual letters but cannot grasp the meaning of whole words. Words must be put together letter by letter before the individual can obtain meaning from them. Even familiar words, such as the aphasic patient's name, must be deciphered on an individual letter basis before meaning can be derived. Iuria (1966a) regarded alexia whioh accompanies temporal leston aphasia as being of two types: alexia accompanying sensory aphasia and alexia accompanying motor aphasia. When sensory aphasia is present, the individual with alexia can easily percetve and recognize the meaning of well established words; however, he is unable to read them aloud. He also oannot read individual segments or letters composing words. The individual with sensory aphasia is hampered in the process of phonetic and literal analysis of words. This 
person is deprived of the support of phonetic analysis and cannot read unfamiliar words.

The individual with motor aphasia will present symptoms of a different type of alexia (Luria, 1966a). As with sensory aphasia, the person with motor aphasia may be able to recognize well known words; however, he will make errors of letter substitutions, e.g., m for $\underline{b}$ and 1 for $t$. He may not be able to put letters into syllables and will read individual letters instead of syllables. The person with this type of alexia cannot perform the process of kinetic synthesis (putting letters into one smooth unit). In other words, the analytic-synthetic process of reading has been severely deranged (Luria, 2966b).

The aphasic patient with alexia will have difficulty with the short words in sentences, e.g., articles, prepositions, conjunctions. He will not be able to understand the semantic relationship between these classes of grammar and other words in the sentence (Eisenson, 1973). The alexic disturbance is generally compounded by a disturbance in visual discrimination and often by an impairment of the visual field (Schuell et al., 1964).

Alexia occurs when the individual reads material silently (Eisenson, 1973). Sasanuma (1974) found this difficulty can be circumvented by having the individual read aloud. Then the material is presented through the auditory channel through which the individual may comprehend the meaning. 
Eisenson (1954) in Examining for Aphasia and Schuell (1965) in the MPDDA have constructed their tests to allow the clinician to learn if alexia is present. Sections of their tests require silent reading and other sections allow the aphasic individual to read the material both visually and aloud. The scores for silent reading and reading aloud are compared. If the score is poorer for silent reading, it is probable the individual has alexia. Woods and Poppel (1974), through tests with a patient with alexia and aphasia, found intensification of the visual stimulus will help overcome the alexic disturbance and increase reading performance. The standard size of book print is from $1 / 16$ to $1 / 8$ inch. Taylor (1958) and Eisenson (197la, 1973) recommend that print size be increased to at least twice the normal size, e.g., $1 / 4$ inch. Increased print size will not only facilitate reading performance but will also reduce the length of time needed to respond to the material (Woods and Poppel, 1974).

\section{Management Guidelines for Reading}

Eisenson (1973) gave the following guidelines to be used with the aphasic patient when reading disabilities are presents

1) begin word at the patient's level of ability;

2) build up sight identification of words, phrases, and short sentences;

3) use the sound-out (phonic) approach for words 
that are not easily read, providing that

the patient has no dysarthria or inclination

to paraphasic errors, or evidence of aud1tory aphasia;

4) comprehension rather than oral style is the objective; therefore, check comprehension by eliciting an oral or written response from the patient;

5) secure interesting reading material at the patient's level of competence;

6) upgrade the level of material as the patient progresses; and

7) make reading materials available that may be read by the patient solely for enjoyment and which will not become the content for instruction.

Eisenson (1973) cautioned the clinician to remember a reading deficit does not occur in isolation. The aphasic patient will have a combination of a few or many of the language and nonlinguistic disabilities considered in this chapter. These disorders can reduce the functional language level over all language modalities, including reading. 


\section{CHAPTER III}

\section{TESTS AND PROCEDURES}

\section{SUBJECTS}

This investigation involved twenty subjects selected from these sources: Rehabilitation Institute of Oregon, Portland Center for Hearing and Speech, Visiting Nurse Association, The Stroke Club, and U.S. Veterans Administration Hospital, Portland, Oregon. All of the subjects had had a cerebro-vascular accident. Brain trauma patients were not used as subjects since, according to Berry and Elsenson (1956), their reacquisition of language skills is generally different than for patients who sustained a cerebro-vascular accident. Each person had been evaluated by a speech pathologist as having an aphasic disorder. The age range of the subjects was forty-two through sixty-five years, with a mean age of fifty-four years. Six of the subjects were females ( 30 percent); fourteen were males (70 percent). A1l of the subjects were nat1ve speakers of Engl1sh who came from families where English was the language spoken in the home during their chllahood. Every subject ras at least three months post-trauma.

The examiner inquired if the subjects used glasses for reading. Seven subjects were instructed to wear their 
glasses during the soreening and testing procedures to ensure they could see the material accurately and avoid fatigue caused by trying to concentrate on witten material when visual acuity was not adequate to complete the task (Buck, 1975). Two prospective subjects with visual field defects, one who said she had a black ring around the center of her fleld of vision (scotoma) and one who said he saw double images (diplopia), were excluded from the study (Wepman, 1951; and Eisenson, 1973).

One subject selected for the investigation was under medication for the control of epileptic selzures which had occurred prior to the time of the study. The subject did not have a seizure within the week prior to the date set for the test; therefore, the testing procedure was not delayed (Young, 1951).

One potential subject had a pre-existing psychlatric disorder at the time of the cerebro-vascular accident which was reported by her physician. This individual was not used in the study because the psychiatric disorder could possibly compound the aphasic disturbance (E1senson, 1960).

One potential subject experienced three transient ischemic attacks within one week prior to the testing date. This subject's physician reported he was not neurologically stable; therefore, he was not used in the study. 
PRE-TEST PROCEDURES

\section{Questionnalre}

A questionnaire was completed by the subject, his spouse, or the person who knew the most about the subject's reading preferences prior to the brain trauma. The results of this inquiry are detalled in Table 1. A subject was not excluded from the study if he or his spouse reported he did not engage in recreational reading prior to the brain trauma since this questionnaire was used for background information.

\section{Screening Test}

The screening test, which was administered to those subjects who were not excluded from the study during the medical prescreening, consisted of two parts. (See Appendix B for exact test material.)

Words. The first part of the screening test consisted of words printed on cards with letters one-quarter inch high, the same size as the print used for the test material (Elsenson, 1973). The words were selected after meeting three criteria:

1) They were in the highest frequency of usage according to Thorndike and Iorge (1944). All of the words fell in the 1 to 500 frequency of usage category.

2) They were words which were in fourth grade spelling books currently in use in Portland Public Schools (Portland Public Schools, 1967a; and Kottmeyer and Claus, 1972a).

3) The words were present either on the subject, 
TABLE I

SUMAARY OF RESULTS OF

SUBJECT QUESTIONNAIRE

\begin{tabular}{|c|c|c|c|c|c|c|c|c|c|c|c|c|c|c|c|c|c|c|c|c|}
\hline Subject & 1 & 2 & 3 & 4 & 5 & 6 & 7 & 8 & 9 & 10 & 11 & 12 & 13 & 14 & 15 & 16 & 17 & 18 & 19 & 20 \\
\hline $\begin{array}{l}\text { Pre-trauma difficulty } \\
\text { with reading }\end{array}$ & & $x$ & & & & & & & & & & & & & & & & & & \\
\hline $\begin{array}{l}\text { Hours per week read } \\
\text { prior to the stroke }\end{array}$ & 0 & 0 & 14 & 5 & 14 & 14 & 14 & 10 & $6 \frac{1}{2}$ & 2 & 16 & 7 & 10 & 16 & 8 & 14 & 14 & 10 & $10 \frac{1}{2}$ & 12 \\
\hline $\begin{array}{c}\text { Type of reading: } \\
\text { Newspapers }\end{array}$ & & & $\mathbf{x}$ & $x$ & $x$ & $x$ & $x$ & $\mathbf{x}$ & $\mathbf{x}$ & $x$ & $x$ & $x$ & $x$ & $x$ & & $x$ & $x$ & $\mathbf{x}$ & $x$ & $x$ \\
\hline Magarines & & & $\mathbf{x}$ & $x$ & $\mathbf{x}$ & $x$ & $\bar{x}$ & $\bar{x}$ & $\bar{x}$ & & $x$ & $x$ & $x$ & $\mathbf{x}$ & $x$ & $\bar{x}$ & $x$ & & $x$ & $x$ \\
\hline Plotion (novels) & & & $\bar{x}$ & & & $\mathbf{x}$ & $\mathbf{x}$ & $x$ & $\bar{x}$ & & $x$ & $x$ & $x$ & $x$ & $x$ & & & $x$ & $x$ & $x$ \\
\hline Technical Journals & & & & & $x$ & & $x$ & & & & $x$ & $x$ & $\bar{x}$ & & $x$ & & $\bar{x}$ & & & \\
\hline $\begin{array}{l}\text { Did he enjoy reading } \\
(n=\text { no, } y=y \in a)\end{array}$ & $n$ & $n$ & $\mathbf{y}$ & $n$ & $y$ & $\mathbf{y}$ & $y$ & $\mathbf{y}$ & $y$ & $n$ & $y$ & $y$ & $y$ & $y$ & $n$ & $\mathbf{y}$ & $y$ & $y$ & $y$ & $y$ \\
\hline $\begin{array}{c}\text { Hours per week reads } \\
\text { now }\end{array}$ & $0 *$ & $0^{*}$ & $\theta *$ & $0 *$ & $1-2$ & $10 *$ & 0 & $0 *$ & $0 *$ & $0 *$ & 1 & $3 \frac{1}{2}$ & $0 *$ & 3t & 0 & 2 & 0 & $0 *$ & $0 *$ & 0 \\
\hline Only in therapy & $x$ & & $x$ & & & & & & & & & & & & & & & & & \\
\hline TV Guide & & $x$ & & & & & & & $x$ & & & & & & & & & & & \\
\hline Practical purposes & & & & $x$ & & & & & & & & & & & & & & & & \\
\hline Beginning & & & & & & $x$ & & & & & & & & & & & & $x$ & & \\
\hline Newspaper & & & & & & & & $x$ & & $x$ & $x$ & $x$ & $x$ & & & $x$ & & & $x$ & \\
\hline Magarines & & & & & & & & & & & & & & $x$ & & & & & & \\
\hline
\end{tabular}

* Total reading time less than one hour per week. 
e.g., body parts, or in the environment of the test room.

The subject was instructed to name each word or to point to an object in the room which corresponded to the test word. The examiner scored each response elther correct or incorrect. Four or more errors out of a total of six responses eliminated the subject from further testing since this number of errors indicated the subject was unable to comprehend the material. Two subjects made more than four errors and were not used in the study.

If a subject stated he could not see the words clearly or that they were blurred or distorted, the test was discontinued and the subject was not included in the study. Two prospective subjects were excluded from the study because they reported visual field defects.

Sentences. Section Two of the screening test was composed of seven simple interrogative and command sentences. No compound or complex sentences were included. The rocabulary in this section was also at the fourth grade level (Portland Public Schools, 1967a; and Kottmeyer and Claus, 1972a).

The first four sentences required a yes/no answer which could be given verbally, could be marked on the test sheet, or could be pointed to for the examiner to underline. The remaining three sentences required a physical gesture from the subject.

Each sentence was scored elther correct or incorrect. 
If the subject missed tro or more of the yes/no questions and more than one of the command (gesture) sentences, he was ellminated from the study. If a subject missed all of the interrogative sentences or all of the command sentences, he was also eliminated from the study. Two prospective subjects missed two of the questions and one of the command sentences. An additional subject missed all three of the command sentences. These three individuals were not included in the study.

\section{READING TEST}

\section{Test Formulation}

The reading test consisted of two paragraphs using fourth grade rocabulary and sentence structure and two peragraphs using sixth grade vocabulary and sentence structure (Wepman, 1951; Gilmore, 1952; Portland Public Schools, $1967 a, b$; and Kottmeyer and Claus, 1972a,b). Each of the paragraphs at the fourth and sixth grade levels was written in both the normal and telegraphic styles. (See Appendix c.)

The reading tests were written following the criteria used by G1Imore (1952). The paragraphs were controlled for:

1) grade level of rocabulary: Testa $4-A$ and $B$ used fourth grade vocabulary and Teats 6-A and $B$ used sixth grade vocabulary (Portland Public Schools, 1967a,b; and Kottmeyer and Claus, 1972a, b);

2) number of words per sentence: Test 4-A had an average of 11 words per sentence, Test 
4-B had an average of 10 words per sentence, Test 6-A had an average of 15 words per sentence, and Test 6-B had an arerage of 13 words per sentence (Gilmore, 1952);

3) number of words per paragraph: Test 4-A had 68 words per paragreph, Test $4-B$ had 62 words per paragraph, both Tests $6-A$ and $B$ had 103 words per paragraph (G1lmore, 1952);

4) multisyliablc words per paragraph: Test 4-A had 21 multisyllabic words per paragraph, Test 4-B had 20 multisyllabic words per paragraph, both Tests $6-A$ and $B$ had 36 multisyllabic words per paragraph (G1Imore, 1952); and

5) percent of multisyllebic words per paragraph: Test 4-A had $30 \%$ mult isy 1 labic words per paragraph, Test 4-B had 33\% multisyllable words per paragraph, both Tests $6-A$ and $B$ had $35 \%$ multisyliabic words per paragraph (Gilmore, 1952).

After the test material was telegraphed, there were the following number of words and sentences per paragraph:

1) Test 4-A: an average of 8 words per sentence and 47 total words in the paragraph;

2) Teat 4-B: an average of 7 words per sentence and 43 total words in the paragraph;

3) Test 6-A: an average of 12 words per sentence and 75 total words in the paragraph; and

4) Test 6-B: an average of 9 words per sentence and 75 total words in the paragraph.

The test questions were written using vocabulary commensurate with the tests, $\theta .8 .$, questions for Tests $4-A$ and B used fourth grade vocabulary and questions for Tests 6-A and B used sixth grade vocabulary (Portland Public Schools, $1967 \mathrm{a}, \mathrm{b}$; and Kottmeyer and Claus, 1972a,b). The word order of the test questions followed scargill (1954) and Schuell (1965) with the verb first in the question to elicit a 
"yes" or "no" response.

\section{Pest Design}

Each subject, because of intra-individual differences caused by the aphasic disturbance, was h1s ow control and, therefore, was observed under both normal (N) and tele-. graphic (I) conditions. An equal number of subjects experienced the $N$ and $I$ treatment condition in the first testing position at both the fourth and sixth grade levels. Figure 3 illustrates how the order of presentation of grammar style was achlered by assigning one-fourth of the subjects to one of four treatment orders. All fourth grade material was presented prior to all sixth grade material for each subject.

The influence of the $\underline{N}$ and $T$ grammar styles was assessed without being contaminated by the influence of the stimulus material (topics). To achieve this result, four topics were used, two at the fourth grade level (Tests 4-A and $B$ ) and two at the sixth grade lerel (Tests 6-A and $B$ ). Normal and telegraphic grammar styles were written for each of the four topics (a total of eight paragraphs as seen in Appendix $C$ ). In summary, each subject received $\underline{N}$ and $\underline{T}$ grammar style tests at both the fourth and sixth grade levels, for a total of four test paragraphs per subject. Order effect of topics was controlled by presenting Topic 4-A before Topic 4-B and Topic 6-A before Topic 6-B. The design represented in PIgure 4 controls order 
Figure 3

CONIROL OF PRESENTATION

OF GRAMMAR STYIE

\begin{tabular}{|c|c|c|c|c|}
\hline & \multicolumn{2}{|c|}{$\begin{array}{l}\text { POURTH GRADE } \\
\text { MATER IAL }\end{array}$} & \multicolumn{2}{|c|}{$\begin{array}{c}\text { SIXTH GRADE } \\
\text { MATERIAL }\end{array}$} \\
\hline & TEST A & TEST B & TEST A & TEST B \\
\hline $\begin{array}{ll}\text { GROUP } & 1 \\
\text { GROUP } & 2 \\
\text { GROUP } & 3 \\
\text { GROUP } & 4\end{array}$ & $\begin{array}{l}\mathrm{N}^{*} \\
\mathrm{~T}^{* *} \\
\mathrm{~N} \\
\mathrm{~T}\end{array}$ & $\begin{array}{l}T \\
N \\
T \\
N\end{array}$ & $\begin{array}{l}N \\
N \\
T \\
T\end{array}$ & $\begin{array}{l}T \\
T \\
N \\
N\end{array}$ \\
\hline
\end{tabular}

Figure 4

DESIGN FOR ADMINISTRATION

OP TEST MATERIAL

\begin{tabular}{lccccc}
\hline & \multicolumn{2}{c}{ FOURTH GRADE } & \multicolumn{2}{c}{ SIXTH GRADE } \\
& & \multicolumn{2}{c}{ MATERIAL } & \multicolumn{2}{c}{ MATERIAL } \\
& TEST A & TEST & & TEST A & TEST B \\
\hline GROUP $1 \quad(n=5)$ & $N_{A}^{*}$ & $T_{B}$ & $N_{A}$ & $T_{B}$ \\
GROUP $2(n=5)$ & $T_{A}^{* *}$ & $N_{B}$ & $N_{B}$ & $T_{A}$ \\
GROUP 3 $3(n=5)$ & $N_{B}$ & $T_{A}$ & $T_{A}$ & $N_{B}$ \\
GROUP $4(n=5)$ & $T_{B}$ & $N_{A}$ & $T_{B}$ & $N_{A}$ \\
\hline
\end{tabular}

$\begin{aligned} * N & =\text { normal } \\ *-T & =\text { telegraphic }\end{aligned}$ 
effects of gremmar style, topic effects, order effects of topics, and precedence of fourth grade materials before ojxth grade materials.

\section{Administration}

Fifty percent of the tests were administered in the homes of the subjects, the other fifty percent were administered in a clinical setting. The rooms used for the tests were as free as possible from distractions.

No testing session lasted longer than thirty minutes. Fourteen subjects received both the screening test and experimental test in one session. The screening test and the test material were administered in multiple sessions for six subjects so they were not fatigued by the presentation of too much material at one time (Wepman, 1951, 1953; Longerich and Bordeaux, 1954; and Taylor, 1958). Five of these subjects received the material in two sessions with a twenty-four hour interval between sessions. One subject recelved the material in three sessions with a twenty-four hour break between the first two sessions and a three hour interval between the second and third test times.

The sessions were conducted during the time of day preferred by each subject. Fifty percent of the subjects received the test material during the morning and fifty percent received it in the afternoon.

The verbal instructions given by the investigator to the subjects were: 
Read this paragraph, then read the questions and mark the right answer. You may have as much time as you like. Go back and look for the right answer if you are not sure (Schuell, 1965).

The questions following each paragraph required a "yes" or "no" response. The subject answered either by checking his answer, pointing to the answer, or giving a verbal answer. If the subject responded verbally or pointed to the answer, the examiner marked the subject's response.

The criteria for failure of comprehension for the fourth grade material was set at four or more incorrect answers out of a maximum of six possible answers. Subjects 3, 17, and $20 \mathrm{missed}$ four, flve, and four answers respectively and were not given the sixth grade material.

\section{DATA ANALYSIS}

Deta relative to the correctness of response of subjects were analyzed as follows: 1) effects of issues and grammar style on correct responses (magnitude) was assessed by a two-by-two repeated measures analysis of variance for fourth grade material; 2) for sixth grade material two $t$ tests of Independent means were performed, one on each grammar style treatment, to ascertain if there was a statist1cally significant aifference between the two topics. This was not done on a two-by-two analysis of variance design (as with fourth grade level analysis) due to the loss of three subjects' responses, resulting in an unequal number 
of subjects for topics at the sixth grade level. Subsequent to this, a single factor repeated measures analysis of variance was employed to assess grammar style effects on the sixth grade level material.

Because of the potential application, heretofore unexamined, of the telegraphic grammar style in this study, It was desirable to perform additional data analysis using a statistic that is maximaliy sensitive to the number of individuals producing treatment difference scores of a large magnitude and in the same direction. Four Wilcoxon $T$ Ordinal-Rank tests were performed:

1) for normal versus telegraphic performance at the fourth grade level material;

2) for normal versus telegraphic performance at the sixth grade level material;

3) for fourth versus sixth grade levels with normal style; and

4) for fourth versus sixth grade levels with telegraphic style.

Finally, a Pearson $\underline{x}$ was computed to assess the relationship, if any, between response time and total correct scores for all subjects. 


\section{CHAPTER IV}

\section{RESULTS AND DISCUSSION}

\section{RESULTS}

The hypothesis under investigation was: Adult aphasic patients will provide significantly more correct answers for telegraphically written material at the fourth grade and sixth grade levels than for normally written material for each grade level. Twenty subjects were used for the study. The original procedure was for each subject to be given both a normal and a telegraphically written paragraph for the fourth and sixth grade levels for a total of four paragraphs for each subject. The subjects were instructed to read each paragraph and answer six questions following 1t. Three subjects falled one paragraph each at the fourth grade level and did not receive the sixth grade material. Because of the unequal number of subjects for the fourth and sixth grade levels, different statistical designs were used to analyze the results at each grade level. Therefore, each grade level will be discussed separately.

Table II presents the total number of correct responses for each subject at the fourth grade level for both normal and telegraphic material. Seventy percent of the subjects areraged above the mean of 8.85 correct answers: 


\section{TABLE II}

TOTAL NUMBER CORRECT RESPONSES

AT THE POURTH GRADE LEVEL

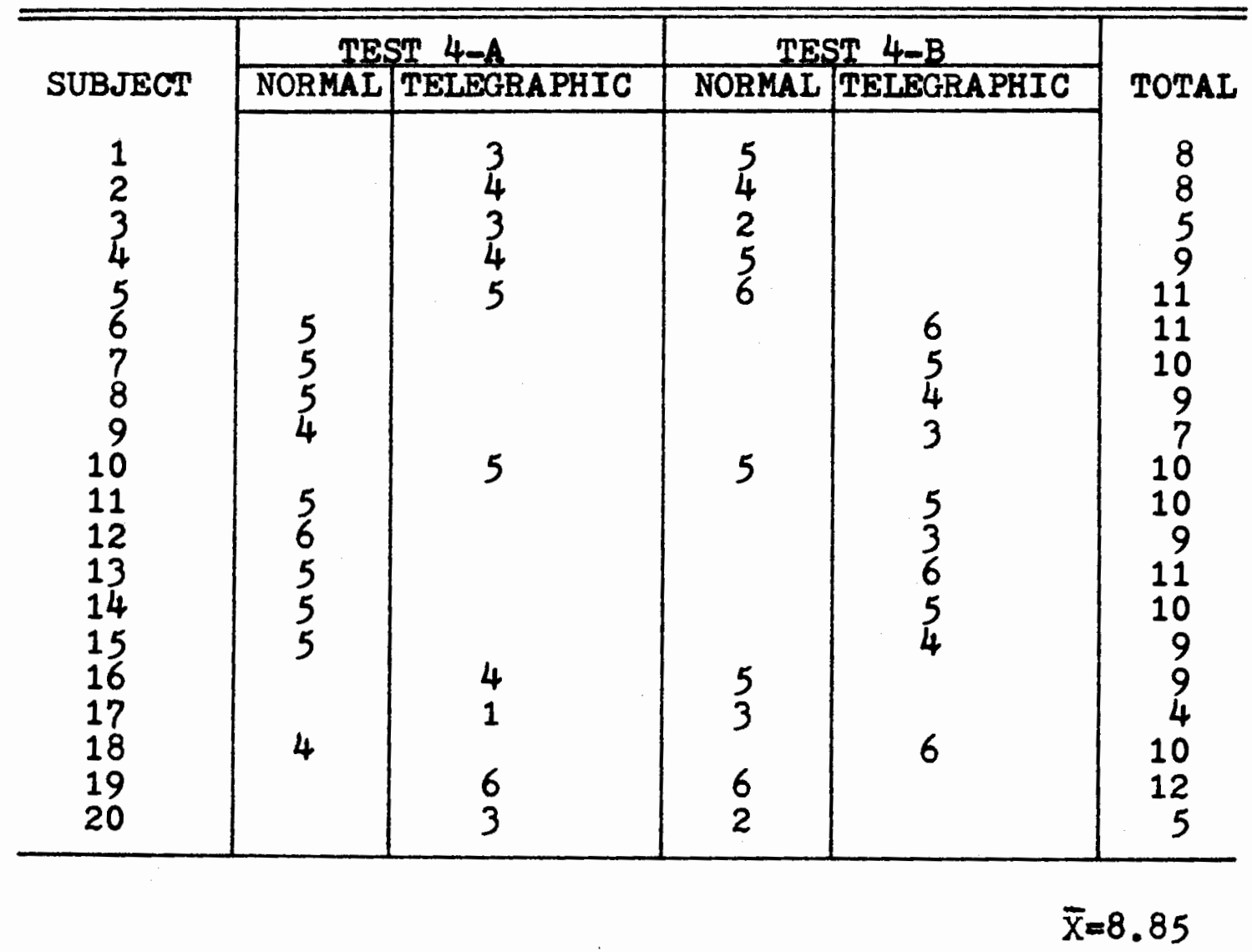


One subject had twelve correct answers, three subjects had eleven, five subjects had ten correct answers, and five subjects had nine correct answers for a total of fourteen subjects with total correct answers above the mean.

F tests for two-way repeated measures analysis of varience analyzing the effects of grammar style and topics on the correctness of response were performed on the fourth grade material. (See Table III.) The $\mathrm{F}$ value for topics was .74 (nonsignificant) and the $F$ value for grammar style was .01 (nonsignificant, $p>.05$ ). The $F$ value for interaction of grammar style and topics was 3.43 (nonsignificant, p >.05).

A one-tailed Wilcoxon T Ordinal-Rank test was utilized to assess the number of subjects who had more correct responses for the telegraphic material for Topics $4-A$ and $B$ when compared to Topics $4-A$ and B normal. (See Table IV.) The $T$ was $2.43(p<.025)$ which shows more correct answers per subject for the telegraphic material for both topics. The range of responses for subjects at the sixth grade level was from five to twelve correct answers. (See Table V.) Serenty-six percent of the subjects averaged above the mean of 8.0 correct responses. Three subjects had twelve correct answers, one had eleven, four had ten correct answers, and five had nine correct answers for a total of thirteen subjects with total correct answers above the mean.

Since three subjects failed one test each at the 
TABIE III

\section{F TEST, ANAIYSIS OF VARIANCE \\ AT THE FOURTH GRADE IEVEL}

\begin{tabular}{|c|c|c|c|c|}
\hline Source of variation & $\mathbf{8 8}$ & $d f$ & MS & $F$ \\
\hline $\begin{array}{l}\frac{\text { Between subjects }}{\text { A (topics) }} \\
\text { Subjects within groups }\end{array}$ & $\frac{416.89}{416.77}$ & $\frac{39}{38}$ & 10.97 & $.01 *$ \\
\hline $\begin{array}{l}\text { Within subjects } \\
B(\text { gramar style }) \\
A B \\
B \times \text { subjects within groups }\end{array}$ & $\begin{array}{r}34.50 \\
.61 \\
2.81 \\
31.08\end{array}$ & $\begin{array}{r}\frac{40}{1} \\
1 \\
38\end{array}$ & $\begin{array}{r}.61 \\
.81 \\
.82\end{array}$ & $.74 *$ \\
\hline
\end{tabular}

nonsignificant, $* p>.05 ; d . f .=1,38$ 
TABLE IV

\begin{abstract}
WILCOXON T ORDINAL-RANK TEST ON NOBMAL AND TELEGRAPHIC IANGUAGE

FOR FOURTH GRADE MATERIAL
\end{abstract}

\begin{tabular}{|c|c|c|c|c|}
\hline \multicolumn{5}{|c|}{ TOPICS 4-A AND 4-B } \\
\hline Normal & Telegraphic & $\mathbf{a}$ & Bank of $\mathrm{a}$ & $\begin{array}{l}\text { Less frequent } \\
\text { sign }\end{array}$ \\
\hline $\begin{array}{l}5 \\
4 \\
2 \\
5 \\
6 \\
5 \\
5 \\
5 \\
4 \\
5 \\
5 \\
6 \\
5 \\
5 \\
5 \\
5 \\
3 \\
4 \\
6 \\
2\end{array}$ & $\begin{array}{l}3 \\
4 \\
3 \\
4 \\
5 \\
6 \\
5 \\
4 \\
3 \\
5 \\
5 \\
3 \\
6 \\
5 \\
4 \\
4 \\
1 \\
6 \\
6 \\
3\end{array}$ & $\begin{array}{r}2 \\
0 \\
-1 \\
1 \\
1 \\
-1 \\
0 \\
1 \\
1 \\
0 \\
0 \\
3 \\
-1 \\
0 \\
1 \\
1 \\
2 \\
-2 \\
0 \\
-1\end{array}$ & $\begin{array}{r}12 \\
-5.5 \\
5.5 \\
5.5 \\
-5.5 \\
5.5 \\
5.5 \\
14 \\
-5.5 \\
5.5 \\
5.5 \\
12 \\
-12 \\
-5.5\end{array}$ & $\begin{array}{l}-5.5 \\
-5.5 \\
-5.5 \\
-12 \\
\frac{T}{34}=2.43^{*}\end{array}$ \\
\hline
\end{tabular}

${ }^{*} p<.025$ 
TABLE V

TOTAL NUMBER CORRECT RESPONSES

AT THE SIXTH GRADE LEVEL

\begin{tabular}{|c|c|c|c|c|c|}
\hline \multirow[b]{2}{*}{ SUBJECT } & \multicolumn{2}{|c|}{ TEST $6-A$} & \multicolumn{2}{|c|}{ TEST $6-B$} & \multirow[b]{2}{*}{ TOTAL } \\
\hline & NORMLI & TELEGBAPHIC & NOBMAL & TELEGRAPHIC & \\
\hline 1 & 5 & & & 4 & 9 \\
\hline 3* & - & & & - & - \\
\hline $\begin{array}{l}4 \\
5\end{array}$ & 6 & 3 & & 6 & 12 \\
\hline $\begin{array}{l}6 \\
7\end{array}$ & & $\begin{array}{l}6 \\
5\end{array}$ & $\begin{array}{l}6 \\
4\end{array}$ & & $\begin{array}{r}12 \\
9\end{array}$ \\
\hline $\begin{array}{l}8 \\
9\end{array}$ & 4 & 4 & 2 & 6 & 10 \\
\hline 10 & & 5 & 5 & & 10 \\
\hline 12 & 4 & & & 4 & 8 \\
\hline 14 & & 4 & $\begin{array}{l}3 \\
5\end{array}$ & & $\begin{array}{l}y \\
9\end{array}$ \\
\hline $\begin{array}{l}15 \\
16\end{array}$ & $\begin{array}{l}5 \\
4\end{array}$ & & & $\begin{array}{l}6 \\
5\end{array}$ & $\begin{array}{r}11 \\
9\end{array}$ \\
\hline $\begin{array}{l}18 \\
19\end{array}$ & 5 & 6 & 6 & 5 & $\begin{array}{l}10 \\
12\end{array}$ \\
\hline $20 *$ & & - & - & & - \\
\hline
\end{tabular}


fourth grade level and consequently did not recelve the s1xth grade material, the total number of subjects for the sixth grade material was seventeen. This caused an unequal number of subjects for each cell of the two-way repeated measures design creating difficulties with analysis of varlance. Therefore, two $\underline{t}$ tests for independent means and $a$ one-way repeated measures analysis of variance were used for the sixth grade material.

Two $\underline{t}$ tests for independent means were applied to assess the effect of grammar styles on correctnes of response. (See Table VI.) A $\underline{t}$ of .13 (nonsignificant) was obtained for Topics $6-\mathrm{A}$ and $B$ normal and a $\underline{t}$ of .18 (nonsignificant) was obtained for Topics $6-A$ and $B$ telegraphic $(p>.05)$.

An $F$ test of variance was performed to ascertain the significance of telegraphic versus normal grammar style. (See Table VII.) An F of .72 (nonsignificant) was obtained $(p>.05)$.

A one-tailed Wilcoxon T Ordinal-Rank test was utilized to assess the number of subjects who had more correct responses for the telegraphic material for Topics $6-\mathrm{A}$ and $\mathrm{B}$ compared to Topics 6-A and B normal. (See Table VIII.) The T was $1.90(p<.025)$ which shows more correct answers per subject for the telegraphic material for both topics.

A Pearson Product Moment Correlation was performed to determine if a relationship existed between latency of response and total correct answers. An $\underline{\underline{r}}$ of -.002 (nonsig- 
TABLE VI

t TESTS FOR INDEPENDENT MEANS

AT THE SIXTH GRADE LEVEL

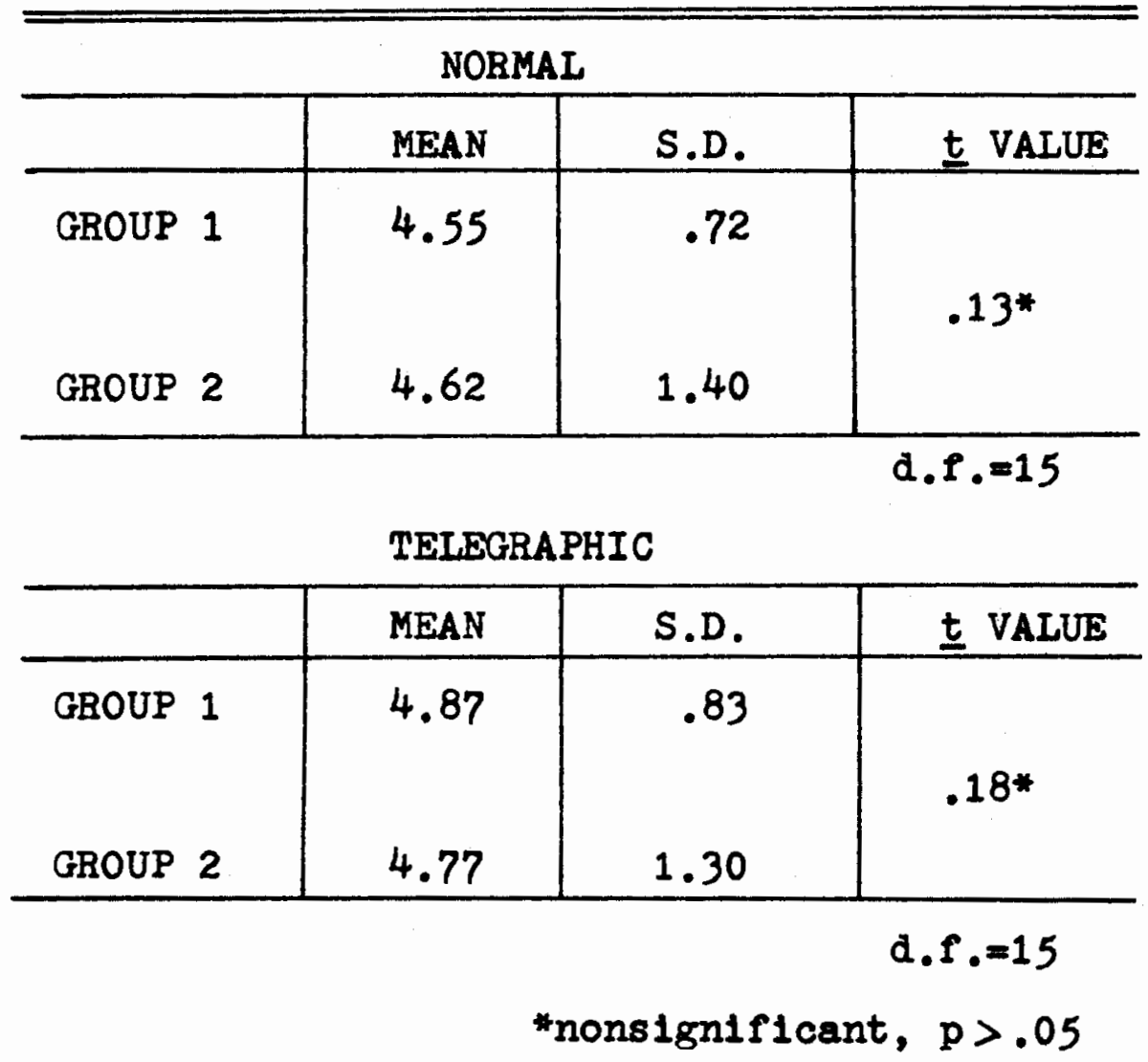


TABIE VII

F TEST, ANALYSIS OF VARIANCE

AT THE SIXTH GRADE IEVEL

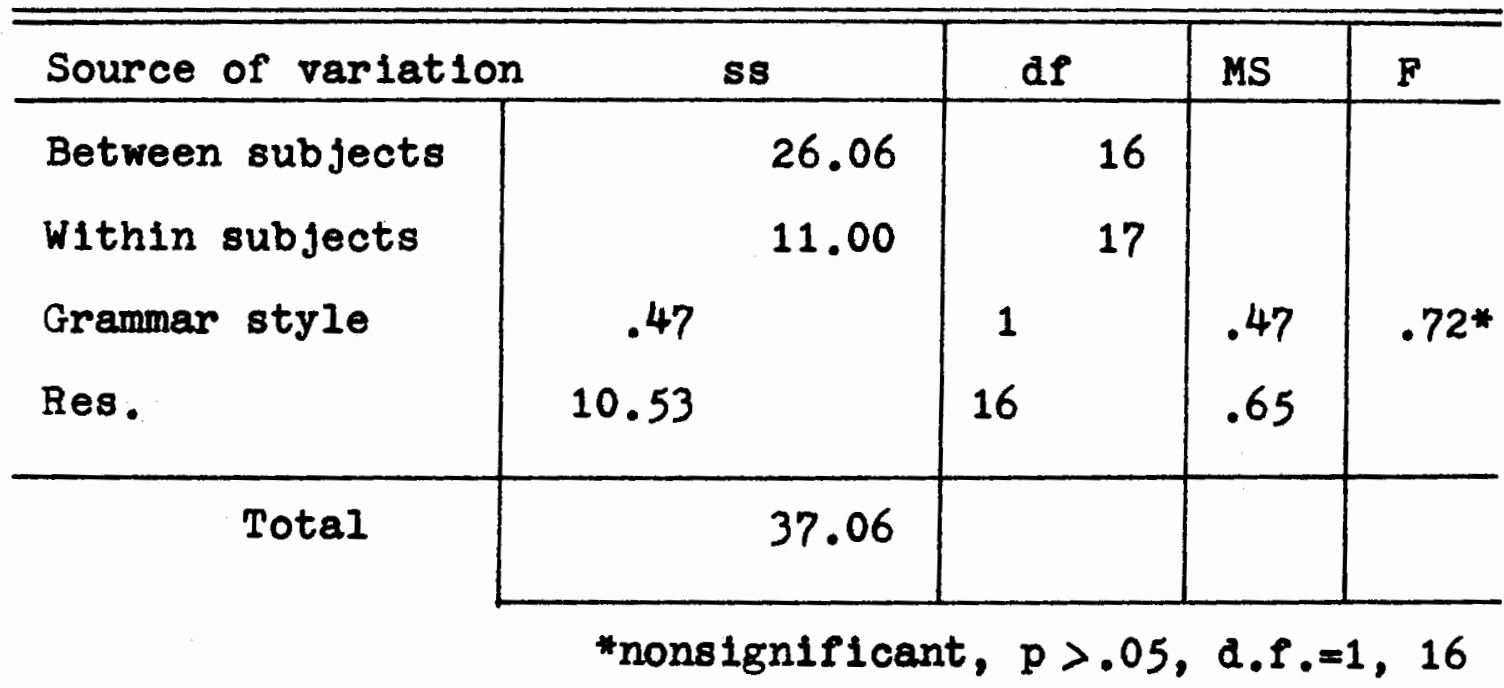


TABIE VIII

WILCOXON T ORDINALARAK TEST ON NORMAL AND TELEGRAPHIC IANGUAGE

FOR SIXTH GRADE MATERIAL

\begin{tabular}{|c|c|c|c|c|}
\hline \multicolumn{5}{|c|}{ TOPICS 6-A AND 6-B } \\
\hline Normal & Telegraphic & $a$ & Rank of $a$ & $\begin{array}{c}\text { Less frequent } \\
\text { sign }\end{array}$ \\
\hline $\begin{array}{l}5 \\
4 \\
3 \\
6 \\
6 \\
4 \\
4 \\
2 \\
5 \\
5 \\
4 \\
5 \\
5 \\
5 \\
4 \\
5 \\
6\end{array}$ & $\begin{array}{l}4 \\
2 \\
5 \\
6 \\
6 \\
5 \\
6 \\
4 \\
5 \\
5 \\
4 \\
4 \\
4 \\
6 \\
5 \\
5 \\
6\end{array}$ & $\begin{array}{r}1 \\
2 \\
-2 \\
0 \\
0 \\
-1 \\
-2 \\
-2 \\
0 \\
0 \\
0 \\
1 \\
1 \\
-1 \\
-1 \\
0 \\
0\end{array}$ & $\begin{array}{r}3.5 \\
8.5 \\
-8.5 \\
-3.5 \\
-8.5 \\
-8.5 \\
\\
3.5 \\
3.5 \\
-3.5 \\
-3.5\end{array}$ & $\begin{array}{r}3.5 \\
8.5 \\
3.5 \\
3.5 \\
19.0 \\
T=1.9^{*}\end{array}$ \\
\hline
\end{tabular}


nificant, $p>.05$ ) was obtained.

For additional information, this investigator compared all fourth grade material (normal and telegraphic) with all sixth grade material (normal and telegraphic) to determine if there was a significant difference in correctness of response at either grade level. Two $\underline{t}$ tests of dependent means were performed. (See Table IX.) The $\underline{t}$ for fourth grade normal and sixth grade normal was .27 (nonsignificant) and the $\underline{t}$ for fourth grade telegraphic and sixth grade telegraphic was .29 (nonsignificant, p >.05). A Wilcoxon $T$ for fourth grade normal and sixth grade normal was $.89(\mathrm{p}<.025)$ and a $\mathrm{T}$ for fourth grade telegraphic and sixth grade telegraphic was 2.77 ( $p<.025)$ showing a bias toward correctness of response at the sixth grade level for both normal and telegraphic material. (See Tables $\mathrm{X}$ and XI.)

\section{DISCUSSION}

The purpose of this investigation was to compare normal and telegraphic writing styles among adult patients with aphasia. The $F$ tests and $\underline{t}$ tests, which are sensitive to the magnitude of response, revealed no significant statistical difference between the two writing styles. Wilcoxon T tests indicated a greater number of subjects gave more correct responses for the telegraphic grammar style than for the normally written material. 
TABLE IX

$t$ TESTS FOR DEPENDENT MEANS

COMPARING TELEGRAPHIC AND

NORMAL PARAGRAPHS

\begin{tabular}{l|c|c|c}
\hline & \multicolumn{3}{|c|}{ NORMAL } \\
\hline Grade 4 & MEAN & S.D. & t VALUE \\
\hline Grade 6 & 4.72 & .82 & \\
\hline & & .72 & \\
\hline
\end{tabular}

TEIEGRAPHIC

\begin{tabular}{l|c|c|c}
\hline & MEAN & S.D. & t VALUE \\
\hline Grade 4 & 4.58 & 1.06 & \\
Grade 6 & 4.82 & 1.07 & \\
\hline
\end{tabular}

*nonsignificant, $p>.05$ 
TABLE X

WILCOXON T ORDINAL-RANK TEST COMPARING

FOURTH AND SIXTH GRADE MATERIAL

FOR NORMAL PARAGRAPHS

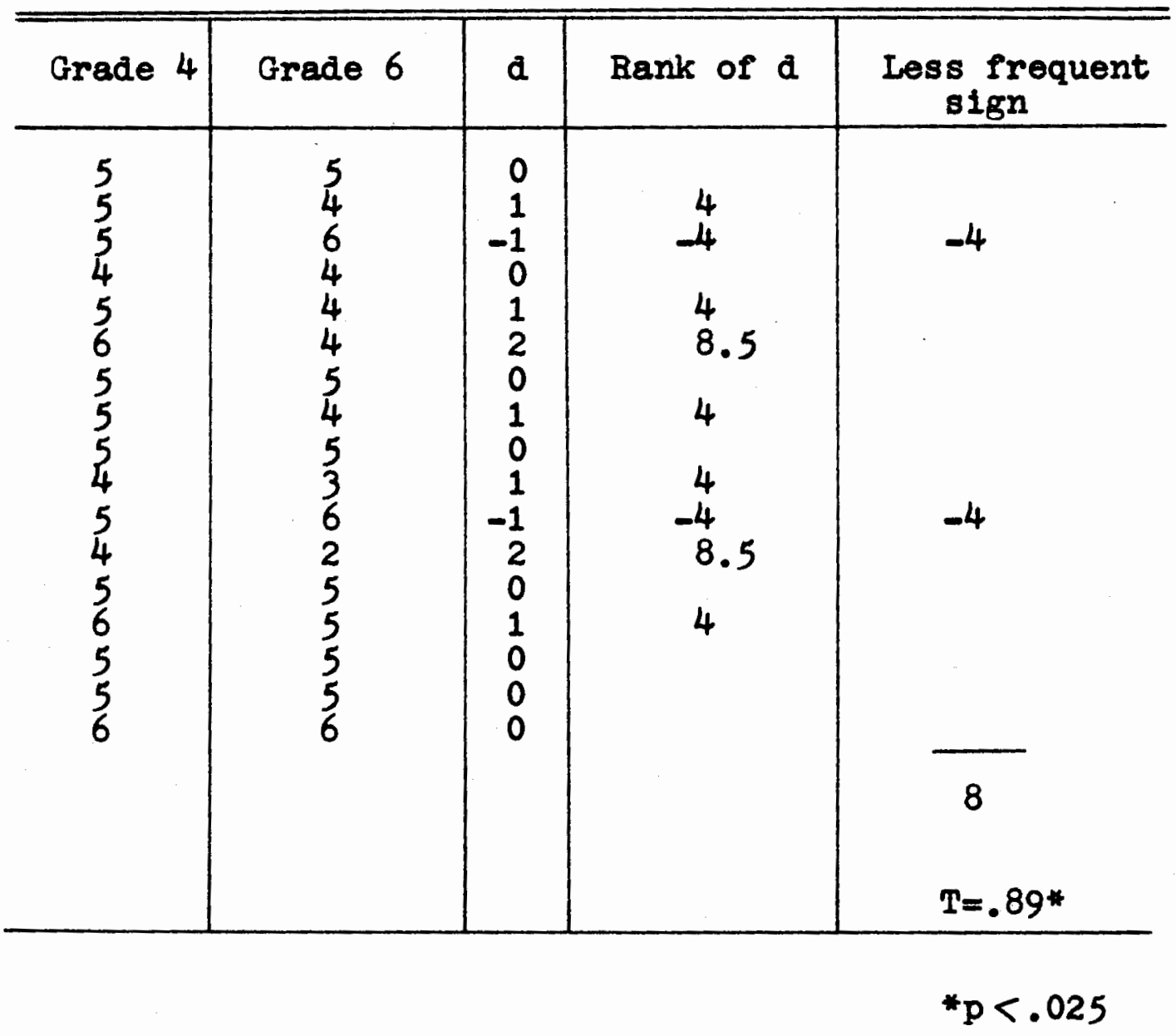


TABIE XI

WILCOXON T ORDINAL-BANK TEST COMPARING

FOURTH AND SIXTH GRADE MATERIAL

FOR TELEGRAPHIC PARAGRAPHS

\begin{tabular}{|c|c|c|c|c|}
\hline Grade 4 & Grade 6 & d & Bank of $d$ & $\begin{array}{l}\text { Less frequent } \\
\text { sign }\end{array}$ \\
\hline $\begin{array}{l}3 \\
6 \\
4 \\
5 \\
5 \\
4 \\
6 \\
6 \\
5 \\
4 \\
3 \\
5 \\
3 \\
6 \\
5 \\
4 \\
6\end{array}$ & $\begin{array}{l}5 \\
2 \\
4 \\
5 \\
5 \\
4 \\
4 \\
6 \\
4 \\
2 \\
6 \\
5 \\
6 \\
4 \\
6 \\
5 \\
5\end{array}$ & $\begin{array}{r}-2 \\
4 \\
0 \\
0 \\
0 \\
0 \\
2 \\
0 \\
1 \\
2 \\
-3 \\
0 \\
-3 \\
2 \\
-1 \\
-1 \\
1\end{array}$ & $\begin{array}{l}-6.5 \\
11 \\
6.5 \\
2.5 \\
6.5 \\
-9.5 \\
-9.5 \\
6.5 \\
-2.5 \\
-2.5 \\
2.5\end{array}$ & $\begin{array}{l}-6.5 \\
-9.5 \\
-9.5 \\
-2.5 \\
-2.5 \\
30.5 \\
T=2.77^{*}\end{array}$ \\
\hline
\end{tabular}

$* p<.025$ 
These results demonstrate that it is easier for some aphasic patients to comprehend telegraphicaliy written materlal than normally written material. Therefore, telegraphically written material may be of value for patients with aphasia who are relearning to read. This type of material may also be used for recreational reading when requested by aphasic patients.

Seventy-five percent of the subjects reported they enjoyed reading prior to their cerebro-vascular accident. The range of correct scores for these subjects was from four to twenty-four correct responses, with a mean of 16.73. Twenty-five percent of the subjects reported they did not enjoy reading before their trauma. The range for this group was fourteen to twenty correct answers $(\bar{X}=17.40)$. Whether or not the subjects enjoyed reading activities prior to their brain trauma does not seem to have influenced their post-trauma comprehension of material; however, to more accurately assess this variable a comparable number of readers and nonreaders would be required as subjects.

Keenan and Brazzell (1975) hypothesized individuals who continued to use reading and writing skills and those persons with the most formal education would be more likely to retain intellectual functions post-trauma. The range of reading time, pre-trauma, for those subjects above the mean of 9.85 hours was from ten to sixteen hours per week. The total correct answers for this group ranged from four to twnety-three $(\bar{X}=17.0)$. 
The range of education above the mean of 12.9 years was 13.5 to 16 years. The range of correct responses for this group was from four to twenty-three answers $(\bar{X}=15.88)$; therefore a correlation between education and correctness of comprehension did not exist for this group. The results of this study do not support the hypothesis of Keenan and Brazzell (1975); however, the sample in this study was not large enough or well enough controlled for education and pre-trauma reading time to either prove or disprove their theory.

Five of the subjects indicated they engage in reading activities at the present time. The range of hours per week is from one to three and one-half hours. These subjects scored from seventeen to twenty-three correct responses around their mean of 19.40 , compared to a total group mean of 16.90 . All five individuals reported they enjoyed reading before their trauma. The mean test time for these subjects was 18.40 minutes, well below the group mean of 31.10 minutes but within one standard deriation below the group mean. The education of this group was 13.3 years, slightly above the total subject mean of 12.9 years. Two theories may account for the performances of these five subjects. It may be that the brain damage sustained was less severe than for the total group, or the damage may possibly have occurred on a site in the brain which did not sererely affect comprehension of language. If the damage was not severe, intellectual functioning and 
educational level may not be as depressed as for the total group (Wepman, 1951; and Matarazzo, 1972). Also, verbel retention span and memory may not be as greatly reduced (Schuell, 1964; and Mossman, 1976). The second theory is that these subjects may have made a fuller recovery from the aphasia with a greater return in intellectual functionIng for all language parameters, including reading. With a greater recovery in reading skills, these subjects may not have experienced as much situational anxiety as the rest of the group when they were exposed to written material; therefore the scores of these five subjects were higher (Matarazzo, 1972).

There were a greater number of incorrect answers for test questions: a) $4-A$, No. 6 ; b) $6-A$, No 6 ; and c) $6-B$, No.6. These questions were:

4-A, No. 6: Should you plant flowers in front of windows?

6-A, No. 6: W11l rockets carry astronauts?

6-B, No. 6: Should families drive the car when going camping?

These questions could be answered in either of two ways: 1) from reading the test paragraph; or 2) from everyday knowledge and experience. The high ratio of incorrect answers may have been caused by the subjects responding to these questions from their own personal experience. Three possible explanations for this test anomaly are: 1) either the subjects had not retained the adminis- 
trator's instructions and were not responding to the test material; 2) the subjects' verbal retention spans were not of sufficient length to retain all the information; or 3) the subjects were experiencing fatigue by the time they reached the sixth question and were not able to respond appropriately. The way to ascertain which of these explanations might be true would be to change the order of the test questions, 1.e., put these three questions in either the Number 1 or Number 2 position. Then if these questions were answered correctly, fatigue or a reduced verbal retention span could be considered as contributing factors for the present preponderance of incorrect answers.

Over seventy-five percent of the subjects responded favorably to the increased print size of the test material. They commented the large print size made it easier for them to read the paragraphs.

The subjects also responded favorably to the vocabulary of the test paragraphs. Subject No. 6 sald she is beginning to learn to read in therapy. She also tries to read the newspaper. This subject said she could read and understand the test paragraphs much easier than either the therapy material or the newspaper. Other subjects made similar comments about the vocabulary to this investigator. 
CHAPTER V

SUMMARY AND IMPLICATIONS

SUMMARY

The purpose of this study was to determine if aphasic patients would have significantly more correct answers for telegraphically written material when compared to normally written material.

Twenty subjects from the greater Portland metropolitan area were selected to be included in this study. The ages of the subjects ranged from forty-two through sixty-five years with a mean of fifty-four years.

The test material consisted of two paragraphs controlled for fourth grade grammar and vocabulary and two paragraphs controlled for sixth grade grammar and vocabulary. A normally written and a telegraphically written paragraph were used for each of the four paragraphs for a total of elght test paragraphs.

The results of this study revealed no statistically significant difference for the magnitude of correct answers for the telegraphically written material; however, a signif1cant number of subjects gave more correct answers for the telegraphic material at both the fourth and sixth grade levels. 
These results demonstrate that it is easier for some aphasic patients to comprehend telegraphically written material then normally written material. Therefore, telegraphically written material may be of value for patients with aphasia who are relearning to read. This type of material may also be used for recreational reading when requested by aphasic patients.

\section{IMPLICATIONS}

\section{Clinical}

The subjects responded favorably to both the large print size and the controlled vocabulary levels. These two items could be incorporated into materials for management sessions to ald in the reacquisition of reading skills for patients with aphasia.

\section{Research}

This investigator suggests further research be conducted with regard to the use of telegraphically written material with aphasic patients. One research project could consist of aphasic patients who were avid readers prior to their brain traume. These subjects would be individuals who report they miss reading for enjoyment since their cerebro-vascular accident. A comparison could be made with this population and a control group of aphasic patients who did not read pre-trauma and did not miss this activity.

A comparison could be made between subjects with pos- 
terior brain lesions and those with anterior damage. This information would have to be clearly delineated in a neurological report. If there is anterior brain damage, it may be associated with agrammatism (Wepman, 1951; and Eisenson, 1973). When agrammatism is present, verbal expression is characterized by the omission of functional words and speech is telegraphic. It may be this type of subject would be more comfortable with the telegraphically written tests and score higher on them. More research needs to be done in this area to determine if there could be a correlation between telegraphic speech and correctness of response on telegraphically written material.

Verbal retention span and memory could be tested by having two groups of subjects. The investigator would read the material to the first group. The second group would read each paragraph one time and not be allowed to refer back to 1t. The two groups could be compared for total number of correct answers comparing normal and telegraphic writing styles.

The Wilcoxon $T$ test results which revealed the subjects gave more correct answers for all sixth grade material than for the fourth grade material ralse more questions than there are answers for at the present time. Theories which could account for this effect are: 1) the large print size recommended by Eisenson (1973) and Sasanuma (1974) could reduce fatigue, and 2) the subjects were more comfortable with the test material and the administrator by the 
time they read the sixth grade material.

Questions for further research which apply to this

test result include: 1) was there a learning effect taking

place, 2) could aphasic patients be subject to less fatigue

than is presently thought to be the case, and 3) do aphasic patients adapt to new material faster than the ilterature suggests (Eisenson, 1973)? All of these theorles and questions will have to be investigated further before any conclusions can be made. 
$\underline{B} \underline{I} \underline{B} \underline{\mathrm{I}} \underline{\mathrm{I}} \underline{\mathrm{G}} \underline{\mathrm{P}} \underline{\mathrm{A}} \underline{\mathrm{P}} \underline{\mathrm{H}} \underline{\underline{Y}}$ 
BIBLIOGRAPHY

AGRANOWITZ, A. and MCKEOWN, M.R. Aphasia Handbook. Springfleld, Ill.: Charles C. Thomas (1970).

BERRY, M. and EISENSON, J. Speech Disorders: Principles and Practices of Therapy. New York: Appleton-CenturyCrofts (1956).

BOONE, D.R. An Adult Has Aphasia. Danville, Ill.: Interstate (1965).

BROOKS, D.N. Long and short term memory in head injured patients. Cortex, 11, 329-340 (1975).

BUCK, M. Dysphasia: Professional Guldance for Family and Patient. Englewood Cliffs, N.J.: Prentice-Hall, Inc. (1968). State Untrersity (1975).

DARLEY, F.I. Diagnosis and Appraisal of Communication D1sorders. Englewood CIIffs, N.J.: Prentice-Hall, Inc. (1964).

DeRENZI, E. and NICHELLI, P. Verbal and non-verbal shortterm memory impairment following hemispheric damage. Cortex, 11, 341-354 (1975).

EISENSON, J. Adult Aphasia: Assessment and Treatment. Englewood Cliffs, N.J.: Prentice-Hall, Inc. (1973).

Aphesia in adults: basic considerations. In L.E. Travis (Ed.), Handbook of Speech Pathology and Audiology. New York: Appleton-Century-Crofts (1971a). Correlates of aphasia in adults. In L.E. TraVis (Ed.), Handbook of Speech Pathology and Audiology.

Examining for Aphasia. New York: The PsychoIogical Corporation (1954).

Therapeutic problems and approaches with aphasic adults. In L.E. Travis (Ed.), Handbook of Speech Pathology and Audiology. New York: Appleton-CenturyCrofts (1971c). 
When and what is aphasia. Monog. Soc. Resear. Ch1ld Dev., 25, 89-95 (1960).

FARREIL, B. Pat and Roald. New York: Bandom House (1969).

GARDNER, H., DENES, G., and ZURIF, E. Critical reading at the sentence level in aphasia. Cortex, 11, 60-72 (1975).

GILMORE, J.V. Gilmore Oral Reading Test. New York: Harcourt, Brace \& World (1952).

GOLDBERG, H.K., and SCHIPFMAN, G.B. Dyslexia: Problems of Reading Disabilities. New York: Grune \& Stratton (1972).

GOUID, G.M. Gould's Pocket Pronouncing Medical Dictionary. Philadelphia: P. Blakeston's Son \& Co., Inc. (1936).

HALPERN, H. Adult Aphasia. New York: The Bobbs-Merrill Co., Inc. (1972).

HARRISON, M.C. Practical English Grammar. Boston: D.C. Heath and Co. (1947).

HARTSTEIN, J. Current Concepts in Dyslexia. St. Louis: C.V. Mosby Co. (1971).

HILGARD, E.R. and ATKINSON, B.C. Introduction to Psychology. New York: Harcourt, Brace \& World, Inc. (1967).

HODGINS, E. Episode: Beport on the Accident Inside My Skn11. New York: Atheneum (1964).

KEENAN, J.S. and BRAZZELL, E.G. Aphasie Language Performance Scales. Murfreesboro, Tenn.: Pinnacle Press (1975).

KOTTMEYER, W. and CLAUS, A. Basic Goals in Spelling: Grade 4. New York: Webster Division, McGraw-Hili Book Company (1972a).

- Basic Goals in Spelling: Grade 6. New York: Webster Division, McGraw-Hill Book Company (1972b).

LEVIN, H.S., GROSSMAN, R.G., and KELLY, P.J. Short-term recognition memory in relation to severity of head injury. Cortex, 12, 175-182 (1976).

LONGERICH, M.C. and BORDEAUX, J. Aphasia Therapeutics. New York: The Macmillan Company (1954). 
LURIA, A.R. Higher Cortical Functions in Man. New York: Bas1c Books, Inc. (1966a).

- Human Brain and Psychological Processes. New York: Harper \& Row (1966b).

MATARAZZO, J.D. Wechsler's Measurement and Appraisal of Aduit Intelligence. Baltimore: The William \& Wilkins Co. (1972).

MCCONNEL, J.V. Understanding Human Behavior; New York: Hoit, $\mathrm{R}$ inehart and Winston, Inc. (1974).

MCNEIL, D. The Acquisttion of Language. New York: Harper \& Row $(1970)$.

MENYUK, P. The Acquisition and Development of Language. Englewood Cliffs, N.J.: Prentice-Hall, Inc. (1971).

MOSSMAN, P.I. A Problem Oriented Approach to Stroke Rehabilitation. Springfield, III.: Charies C. Thomas $(1976)$.

PARISI, D. and PIZZAMIGLIO, L. Syntactic comprehension in aphasia. Cortex, 6, 204-215 (1970).

PENFIELD, W. and ROBERTS, I. Speech and Brain-Mechanisms. Princeton, N.J.: Princeton University Press (1959).

PERKINS, W.H. Speech Pathology: A Behavioral Science. St. Louis: C.V. Mosby Co. (1971).

POPPEL, E. and SHATTUCK, S.R. Reading in patients with brain wounds involving the central visual pathways. Cortex, 10, 84-88 (1974).

REITAN, R.M. Problems and prospects in studying psycholiogical correlates of brain lesions. Cortex, 2, 127154 (1966).

RUSK, H.A. Rehabilitation Medicine. St. Louis: C.V. Mosby (1971).

SASANUMA, S. Kanj1 versus kana processing in alexia with transient agraphia: a case report. Cortex, 10, 8997 (1974).

SCARGILL, M. Modern linguistics and recovery from aphasia. J. Speech Hearing Dis., 19, 507-513 (1954).

SCHUELL, H. Aphasia Theory and Therapy. Baltimore: University Park Press (1974). 
- Differential Diagnosis of Aphasia with the Minnesota Test. Minneapolis: Univ. of Minnesota Press (1965).

JENKINS, J. and JIMENEZ-PABON, E. Aphasia in AduIts. New York: Harper \& Row (1964).

SHAFER, S.Q., BROWN, B., BROWN, B. and RICHTER, R.W. Stroke: early portents of functional recovery in black patients. Arch. Physical Med, Rehab., 55, 264$268(1974)$.

SHERMAN, M. Cerebrovascular Disease. Bethesda, Md.: U.S. Department of Health, Education and Welfare (1964).

SHEWAN, C.M. and CANTER, C.J. Effects of vocabulary, syntax and sentence length on auditory comprehension in aphasic patients. Cortex, 7, 209-226 (1971).

SIEGEL, S. Nonparametric Statistics for the Behavioral Sciences. New York: McGraw-Hill (1956).

SKELLY, M. Aphasic patients talk back. Am. J. Nursing, July (1975).

SMITH, G.W. Care of the Patient with a Stroke. New York: Springer Pub. Co., Inc. (1967).

SMITH, I.W. and PHILIPPUS, M.J. Neuropsychological Testing in Organic Brain Dysfunction. Springfield, IIl.: Charles C. Thomas (1969).

TAYLOR, A. and WARRINGTON, E.K. Visual agnosia: a single case report. Cortex, $7,152-161$ (1971).

TAYIOR, M. Understanding Aphasia: A Guide for Family and Friends. New York: Institute of Physical Medicine and Rehabilitation, New York University - Bellevue Medical Center (1958).

The Portland Speller: Grade 4. Portland, Ore.: Portland Public Schools, School District No. 1 (1967a).

The Portland Speller: Grade 6. Portland, Ore.: Portland Public Schools, School District No. 1 (1967b).

THORNDIKE, E. and LORGE, I. Teachers Word Book of 30,000 Words. New York: Teachers College, Columbia University (1944).

ULLMAN, M. Behavioral Changes in Patients Following Strokes. Springfield, Ill.: Charles C. Thomas (1962). 
WEINSTEIN, S. and TEUBER, $H$. Effects of penetrating brain injury on intelligence test scores. Science, 125, 1036-1037 (1957).

WEPMAN, J.M. A conceptual model for the processes involved in recovery from aphasia. J. Speech Hearing D1s., $18,4-13$ (1953).

Pres's Company (1951).

WERTZ, R.T., MESSERT, B., COLIINS, M., ROSENBEK, J.C. and $K A O, C . C . R$ ight-hemisphere language dominance in a case of left-hemisphere arteriovenous malformation. J. Speech Hearing D1s., 42, 106-112 (1977).

WINER, B.J Statistical Principles in Experimental Design. New York: McGraw-Hill (1962).

WINT, G. The Third Killer. New York: Abelard-Schuman (1967).

WOOD, N.E. Language disorders in chilaren. Monog. Soc. Resear. Child Dev., 25, 15-23 (1960).

WOODS, B.T. and POPPEL, E. Ef fect of print size on reading time in a patient with verbal alexia. Neuropsycholog $1 \mathrm{a}, 12,31-41$ (1974).

YOUNG, J.Z. Doubt and Certainty in Sclence: A Blologist's Reflections on the Brain. Oxford: Clarendon Press (1951).

ZANKEL, H.T. Stroke Rehabilitation: A Guide to the Rehabilitation of an Adult Patient Following a Stroke. Springfield, Ill.: Charles C. Thomas (1971). 
APPENDIX A

READING HISTORY QUESTIONNAIRE

\section{Name}

1. Did he have any difficulty with reading prior to his present hospitalization? yes/no

2. Average number of hours per week he read prior to his present hospitalization

3. What type of material did he read?

a. newspapers

b. magazines

c. fiction (novels)

d. technical journals and magazines

4. Did he enjoy reading?

yes/no

5. Average number of hours per week he reads now

RELEASE OF INFORMATION

I give my consent to use information gained from this evaluation for thesis and research publication purposes.

\section{Name}

Address

Phone number

Date 


\section{APPENDIX B}

\section{SCREENING TEST}

Words :
1. ear
5. hand
2. table
6. hatr
3. door
7. floor
4. book
8. head

Question sentences:

1. Is it raining today?

yes no

2. Is my wife waiting?

yes no

3. Is the coffee on the table?

yes no

4. Is my car outside?

yes no

Command sentences:

1. Put your hand on the table.

2. Count to five.

3. Pick up the pencil. 


\section{APPENDIX $C$}

\section{TEST MATERIAL}

Grade 4-A (Normal)

You can use some easy tricks to keep your house cooler this summer. Do not use your oven for cooking any more than necessary. Open your windows at night to let cooler air into the house. Close the windows in the morning to keep the house cool longer. Pull curtains over windows to keep sunlight out. Trees planted in front of windows will provide shade from the sun.

Are there ways you can keep your house cooler?

Should you use your oren only when necessary?

yes no

Should you close windows at night?

Should you close windows during the day?

Should you open curtains during the day?

Should you plant flowers in front of windows?

yes no

yes no

yes no

Yes no

yes no

Grade 4-A (Telegraphic)

You can use tricks to keep house cooler this summer. Do not use oven more than necessary. opening windows at night lets cooler air in house. Closing windows in morning keeps house cool. Pulling curtains over windows keeps sunlight out. Trees planted in front of windows provide shade.

Are there ways you can keep your house cooler? yes no Should you use your oven only when necessary? yes no Should you close windows at night?

Should you close windows during the day?

Should you open curtains during the day?

yes no

Should you plant flowers in front of windows?

yes no

yes no

yes no 
Test 4-B (Normal)

The common cold is very unpleasant. Colds occur more often in the winter than in the summer. Women catch more colds than men. People who smoke do not have more colds than other people. Parents of young children have more colds than other people because children bring home "cold bugs" from school. We contract colds from others when they cough or sneeze.

Is a cold unpleasant?

Do colds occur more often in the summer?

Do men have more colds than women?

Do people who smoke have more colds?

Do parents of young children have more colds?

Do we catch colds when people sneeze?

$\begin{array}{ll}\text { yes } & \text { no } \\ \text { yes } & \text { no } \\ \text { yes } & \text { no } \\ \text { yes } & \text { no } \\ \text { yes } & \text { no } \\ \text { yes } & \text { no }\end{array}$

Test 4-B (Telegraphic)

The common cold is unpleasant. Colds occur more often in the winter. Women catch more colds. People who smoke do not have more colds. Parents of young children have more colds than other people. We contract colds when others cough or sneeze.

Is a cold unpleasant?

Do colds occur more often in the summer?

yes no

Do men have more colds than women?

Do people who smoke have more colds?

Do parents of young children have more colds?

yes no

Do we catch colds when people sneeze?

yes no

yes no

yes no

yes no 
Test 6-A (Normal)

In the future, spece exploration in our solar system will focus on the planets Mars and Jupiter. Scientists do not know if there is life on the planet Mars and exploration will finally give us an answer. A camera in a spaceship will take pictures of the planet and send them back to Earth. Scientists will examine the pictures and then the question of life on Mars will be solved. The planet Juplter, which is similar to Earth, will also be explored for 1ife. The rockets used for planet exploration will not carry astronauts. The reason is to avold carrying human germs to the planet's environment.

W1Il space exploration focus on Saturn?

Do scientists know if there is life on Mars?

Will a camera take pictures of Mars?

Will scientists examine the pictures?

Will Jupiter be explored for life?

W1ll rockets carry astronauts?

$\begin{array}{ll}\text { yes } & \text { no } \\ \text { yes } & \text { no } \\ \text { yes } & \text { no } \\ \text { yes } & \text { no } \\ \text { yes } & \text { no } \\ \text { yes } & \text { no }\end{array}$

Test 6-A (Telegraphic)

In the future, space exploration will focus on Mars and Jupiter. Scientists do not know if there is life on Mars and exploration will give an answer. A camera will. take pictures of the planet and send them to Earth. Scientists will examine the pictures and solve the question of life on Mars. Jupiter will also be explored for life. Rockets used for exploration will not carry astronauts to avold carrying germs to the planets.

Will space exploration focus on Saturn? Do scientists know if there is life on Mars? Will a camera take pictures of Mars? Will scientists examine the pictures? Will Jupiter be explored for life? Will rockets carry astronauts? 
Test 6-B (Normal)

Gasoline prices have risen to an all time high today. If people can discover ways to save gasoline, they will also save money. When driving to the store for groceries, invite a neighbor or friend to go shopping with you. Pick up another guest when you are going to a party. Taking only one automobile saves gasoline and also prevents engine wear. Whenever possible, do not drive your car but ride a city bus instead. Children should walk or ride bicycles instead of being driven around by parents. Families can ride bicycles when going on overnight camping trips instead of using the car.

Are gasoline prices low today? Will people save money if they save gasoline? yes no Should you take a nelghbor shopping to save

Should you take

yes no

Should children ride in cars instead of walking?

Should families drive the car when going camping?

yes no

yes no

yes no

yes no

Test 6-B (Telegraphic)

Gasoline prices have risen to all time high. If people can save gasoline, they will also save money. When driving to store for groceries, invite neighbor or friend to go with you. Pick up another guest when going to party. Taking one automobile saves gasoline and prevents engine wear. Whenever possible, do not drive but ride a bus. Children should walk or ride bicycles. Families can ride bicycles when going camping instead of using the car.

Are gasoline prices low today?

Will people save money if they save gasoline?

Should you take a nelghbor shopplng to save gasoline?

Should you take a bus instead of using your car?

Should children ride in cars instead of walking?

Should families drive the car when going camplng?

yes no

yes no

yes no

yes no

yes no

yes no 
APPENDIX D

SUBJECTS ' AGE, READING

AND TEST PROFILES

\begin{tabular}{|c|c|c|c|c|c|c|c|}
\hline Subject & Até & $\begin{array}{c}\text { Educa- } \\
\text { tion }\end{array}$ & $\begin{array}{l}\text { Enjoy } \\
\text { Reading } \\
\text { Prior? }\end{array}$ & $\begin{array}{l}\text { Weal } \\
\text { Houra } \\
\text { Prior }\end{array}$ & $\begin{array}{l}\text { Rly } \\
\text { Read } \\
\text { Post }\end{array}$ & $\begin{array}{l}\text { Test } \\
\text { Read ing } \\
\text { Time* }\end{array}$ & $\begin{array}{l}\text { Total } \\
\text { Correct } \\
\text { Answers }\end{array}$ \\
\hline $\begin{array}{r}1 \\
2 \\
3 \\
4 \\
5 \\
6 \\
7 \\
8 \\
9 \\
10 \\
11 \\
12 \\
13 \\
14 \\
15 \\
16 \\
17 \\
18 \\
19 \\
20\end{array}$ & $\begin{array}{l}54 \\
52 \\
59 \\
55 \\
42 \\
60 \\
57 \\
50 \\
47 \\
61 \\
65 \\
47 \\
54 \\
60 \\
54 \\
65 \\
51 \\
46 \\
47 \\
51\end{array}$ & $\begin{array}{l}12.5 \\
10 \\
14 \\
12 \\
15 \\
15 \\
12 \\
12.75 \\
14 \\
12 \\
12 \\
13.5 \\
13 \\
12 \\
16 \\
14 \\
14 \\
12 \\
12 \\
12\end{array}$ & $\begin{array}{l}\text { no } \\
\text { no } \\
\text { yes } \\
\text { no } \\
\text { yes } \\
\text { yes } \\
\text { yes } \\
\text { yes } \\
\text { yes } \\
\text { no } \\
\text { yes } \\
\text { yes } \\
\text { yes } \\
\text { yes } \\
\text { no } \\
\text { yes } \\
\text { yes } \\
\text { yes } \\
\text { yes } \\
\text { yes }\end{array}$ & $\begin{array}{c}0 \\
0 \\
14 \\
5 \\
14 \\
14 \\
14 \\
10 \\
6.5 \\
2 \\
16 \\
7 \\
10 \\
16 \\
8 \\
14 \\
14 \\
10 \\
10.5 \\
12\end{array}$ & $\begin{array}{c}0 \\
0 \\
0 \\
0 \\
1-2 \\
0 \\
0 \\
0 \\
0 \\
0 \\
1 \\
3.5 \\
0 \\
3.5 \\
0 \\
2 \\
0 \\
0 \\
0 \\
0\end{array}$ & $\begin{array}{l}45 \\
60 \\
60 \\
40 \\
20 \\
80 \\
30 \\
25 \\
20 \\
35 \\
20 \\
30 \\
20 \\
15 \\
25 \\
7 \\
15 \\
25 \\
30 \\
20\end{array}$ & $\begin{array}{r}17 \\
14 \\
5 \\
17 \\
23 \\
23 \\
19 \\
21 \\
13 \\
19 \\
20 \\
17 \\
20 \\
19 \\
20 \\
18 \\
4 \\
20 \\
24 \\
5\end{array}$ \\
\hline
\end{tabular}

*minutes 